\title{
LA DESAPARICIÓN FORZADA DE PERSONAS: NATURALEZA, FUENTES Y JERARQUÍA. COMENTARIO A LA SENTENCIA DEL TRIBUNAL CONSTITUCIONAL RELATIVO A LA CONVENCIÓN INTERAMERICANA SOBRE DESAPARICIÓN FORZADA DE PERSONAS
}

Gonzalo Aguilar Cavallo

Profesor de Derecho Internacional Público y Derechos Humanos de la Universidad de Talca gaguilar@utalca.cl

"Con el tiro habían abierto un agujero en esa perfección de que se vanagloriaban. Morir odiándolos, esa era la libertad. Vamos a ver, Winston, ¿cómo afirma un hombre su poder sobre el otro? Winston pensó un poco y respondió: Haciéndolo sufrir:

Exactamente. Haciéndole sufrir. No basta con la obediencia. Si no sufre, ¿cómo vas a estar seguro de que obedece tu voluntad y no la suya propia?

El poder radica en infligir dolor y humillación.

El poder está en la facultad de hacer pedazos los espíritus, $y$ volverlos a construir dándoles nuevas formas elegidas por ti".

George OrWeLl, 1984

\section{INTRODUCCIÓN}

Mediante sentencia de fecha 5 de septiembre de 2003 el Tribunal Constitucional chileno acogió el requerimiento de inconstitucionalidad del Proyecto de Acuerdo que aprueba

1 Doctor en Derecho, MA en Relaciones Internacionales, LLM en Derechos Humanos y Derecho Humanitario. El autor quiere agradecer el valioso soporte de Rébecca Steward en la elaboración de este artículo. Con todo, cualquier error u omisión es responsabilidad exclusiva del autor. 
la Convención Interamericana sobre Desaparición Forzada de Personas (en adelante, la CIDFP), adoptada el 9 de junio de 1994 en Belén, Brasil, durante el XXIV Período Ordinario de Sesiones de la Asamblea General de la Organización de Estados Americanos y declaró la inconstitucionalidad de forma respecto del referido Proyecto de Acuerdo.

La desaparición forzada de personas es una figura penal que ha nacido y se ha regulado por el Derecho Internacional, formando, actualmente, parte del Derecho Internacional Penal y del Derecho Internacional de los derechos humanos. En consecuencia, desde el comienzo de este comentario, conviene tener presente que cuando hablamos del crimen de desaparición forzada de personas estamos netamente en el terreno del Derecho Internacional Penal. Esta última idea es relevante para el intérprete y aplicador del derecho y será relevante durante el curso de este comentario, por cuanto todos los razonamientos, reflexiones, interpretaciones y argumentaciones deben estar regidos y orientados por principios propios del orden jurídico internacional y no, salvo remisión expresa -o explícita incorporación del Derecho Internacional al derecho interno-, por las reglas y principios propios del orden doméstico.

\section{I \\ HECHOS}

El proyecto de acuerdo que aprobó la CIDFP fue impugnado por un número determinado de senadores, con fecha 30 de julio de 2003, solicitando que se declarara la inconstitucionalidad del Proyecto de Acuerdo, fundamentalmente "con el objeto de que se declare la inconstitucionalidad del proyecto de acuerdo que aprueba la Convención Interamericana sobre Desaparición Forzada de Personas, adoptada el 9 de junio de 1994 en Belén, Brasil, durante el XXIV Período Ordinario de Sesiones de la Asamblea General de la Organización de Estados Americanos, en atención a que la consagración que en ella se hace del principio de universalidad de la jurisdicción, establecido en su artículo IV, inciso segundo, es contraria a los artículos $5^{\circ}, 6^{\circ}, 7^{\circ}, 19, \mathrm{~N}^{\circ} 3^{\circ}, 73,74$ y 79 de la Constitución, lo que afecta la totalidad del Tratado que se impugna”. ${ }^{2}$

Para los efectos de este comentario, conviene tener presente el texto del referido artículo IV de la CIDFP, el cual reza como sigue: "Los hechos constitutivos de la desaparición forzada de personas serán considerados delitos en cualquier Estado Parte. En consecuencia, cada Estado Parte adoptará las medidas para establecer su jurisdicción sobre la causa en los siguientes casos:

a. Cuando la desaparición forzada de personas o cualesquiera de sus hechos constitutivos hayan sido cometidos en el ámbito de su jurisdicción;

2 Tribunal Constitucional de Chile: Requerimiento formulado por Senadores para que se declare la inconstitucionalidad del proyecto de acuerdo que aprueba la Convención Interamericana sobre Desaparición Forzada de Personas, adoptada el 9 de junio de 1994 en Belén, Brasil, durante el XXIV Período Ordinario de Sesiones de la Asamblea General de la Organización de Estados Americanos. Rol N 383-2003. Sentencia de fecha 5 de septiembre de 2003, p. 1. 
b. Cuando el imputado sea nacional de ese Estado;

c. Cuando la víctima sea nacional de ese Estado y éste lo considere apropiado.

Todo Estado Parte tomará, además, las medidas necesarias para establecer su jurisdicción sobre el delito descrito en la presente Convención cuando el presunto delincuente se encuentre dentro de su territorio y no proceda a extraditarlo.

Esta Convención no faculta a un Estado Parte para emprender en el territorio de otro Estado Parte el ejercicio de la jurisdicción ni el desempeño de las funciones reservadas exclusivamente a las autoridades de la otra Parte por su legislación interna".

\section{II LO QUE DIJO LA SENTENCIA}

La sentencia del Tribunal Constitucional sobre la CIDFP abordó dos aspectos relevantes relacionados con el control de constitucionalidad de los tratados internacionales, a saber, el examen de constitucionalidad sobre normas no autoejecutables y el examen de constitucionalidad de forma vinculado al control del procedimiento de aprobación del tratado en el Parlamento.

\section{A) Normas convencionales autoejecutables y no autojecutables}

Como argumentación en contra del requerimiento de inconstitucionalidad, el Presidente de la República indica que "el artículo IV, inciso segundo, de la Convención impugnada por los requirentes es una norma no autoejecutable y [...] esta clase de preceptos no autoejecutables no pueden entrar en conflicto con la Constitución, al no generar normas de aplicación directa”.

En esta materia el Tribunal Constitucional se pronuncia rechazando la argumentación del Presidente de la República. En efecto, el Tribunal señala que la tesis de la no autoejecutabilidad "no resulta aplicable en el presente caso, pues el artículo IV, inciso segundo, de la Convención en estudio, no puede calificarse como una norma no autoejecutable, por la consecuencia especial que deriva de su aplicación, de conformidad a sus propios términos. En efecto, el precepto aludido cobra plena eficacia, y se basta a sí mismo, ratificado que sea por Chile el Tratado, ya que cualquier Estado Parte de él que lo haya incorporado a su ordenamiento jurídico interno y hubiese ajustado su legislación, tendrá jurisdicción para juzgar a un chileno por actos cometidos en Chile que configuren el delito de desaparición forzada de personas, bastando para ello que no proceda extraditarlo, independientemente de si Chile adecuó o no su propia legislación". ${ }^{3}$

3 Tribunal Constitucional de Chile: Requerimiento formulado por Senadores para que se declare la inconstitucionalidad del proyecto de acuerdo que aprueba la Convención Interamericana sobre Desaparición Forzada de Personas, adoptada el 9 de junio de 1994 en Belén, Brasil, durante el XXIV Período Ordinario de Sesiones de la Asamblea General de la Organización de Estados Americanos. Rol N ${ }^{\circ}$ 383-2003. Sentencia de fecha 5 de septiembre de 2003. Considerando $3^{\circ}$. 
Pero además, con el fin de guiar en la interpretación de los preceptos en materia de constitucionalidad, el Tribunal Constitucional incorpora un obiter dictum a propósito de la distinción entre normas autoejecutables (self-executing) y normas no autoejecutables (non self-executing) que viene a precisar la distinción ya efectuada en un fallo anterior.

En efecto, en el caso sobre el Requerimiento respecto del Convenio $N^{\circ} 169$, Sobre Pueblos Indígenas y Tribales en Países Independientes, adoptado por la Organización Internacional del Trabajo, el 27 de junio de 1989, el Tribunal Constitucional afirmó expresamente que "[l]os tratados, para su aplicación en el orden interno de un país, pueden contener dos tipos de cláusulas, denominadas por la doctrina "self executing" $\mathrm{y}$ "non self executing". Las primeras, son las que tienen el contenido y precisión necesarias que las habilita para ser aplicadas sin otro trámite como fuente del derecho interno. En otros términos, son autosuficientes, y entran a la legislación nacional cuando el tratado que las contiene se incorpora al derecho vigente. Las segundas, son aquellas que requieren para su entrada en vigencia de la dictación de leyes, reglamentos o decretos que las implementen y, en tal evento, las haga aplicables como fuente del derecho interno. En otras palabras, imponen la obligación al Estado, para que en uso de sus potestades públicas, sancione la normativa necesaria para que por esa vía les dé vigencia efectiva. Pueden existir tratados que sólo contengan cláusulas autoejecutables y otros que sólo contengan no ejecutables, como puede un mismo tratado contener unas y otras. Esta precisión resulta determinante para pronunciarse sobre la inconstitucionalidad de los preceptos del tratado, toda vez que aquellos cuyas normas o algunas de ellas requieran, para tener fuerza interna, de una actividad legislativa o administrativa posterior, no pueden, por esa razón, entrar en contradicción desde pronto con el ordenamiento constitucional ya que no son normas vigentes ni tampoco lo serán cuando el Presidente de la República ratifique el tratado si es que es aprobado por el Congreso y el Ejecutivo decide así hacerlo. Si los preceptos que se deben dictar para implementarlo, llegaren a contener disposiciones contrarias a la Constitución, ello será decidido en su oportunidad por los órganos de control de constitucionalidad que la propia Carta Fundamental establece. Siendo así, en cada caso particular deberá previamente decidirse por este Tribunal si las disposiciones del tratado son o no autoejecutables y, por ende, si quedarán incorporadas, sin necesidad de otro acto de autoridad, al derecho interno. Sólo en el evento de que la norma sea autoejecutable, el Tribunal debe en esta instancia jurisdiccional pronunciarse sobre su constitucionalidad". ${ }^{4}$

El Tribunal Constitucional, en su examen de constitucionalidad de la CIDFP, aumentó las hipótesis de control de constitucionalidad, a casos de normas internacionales convencionales non self-executing, pero cuya aprobación y aplicación pueda conducir a inconstitucionalidades de fondo que afecten a la Convención. En este caso, el control de constitucionalidad del tratado no podría verse limitado por tratarse, la(s) norma

4 Tribunal Constitucional de Chile: Requerimiento respecto del Convenio $N^{\circ} 169$, Sobre Pueblos Indígenas y Tribales en Países Independientes, adoptado por la Organización Internacional del Trabajo, el 27 de junio de 1989. Rol No 309-2000. Sentencia de fecha 4 de agosto de 2000. Considerando $48^{\circ}$, p. 45. 
impugnada, de una norma non self executing. Así, en el requerimiento contra la CIDFP, el Tribunal Constitucional señaló claramente que la distinción entre normas autoejecutables y normas no autoejecutables "desde luego y naturalmente, tiene una excepción importante. Esta consiste en que si la norma no autoejecutable requiere de la aprobación por el Estado de Chile de preceptos que, conforme a la Constitución, conduzcan o puedan conducir a una inconstitucionalidad de fondo que afecte a la Convención, como podría ocurrir en la especie, no resulta aceptable ni razonable postergar una resolución sobre ella, habida consideración, en especial, de las disposiciones sobre cumplimiento de los tratados, con singular significación de su artículo 27, contenidas en la Convención de Viena publicada en el Diario Oficial de 22 de junio de 1981 ". ${ }^{5} \mathrm{~A}$ mayor abundamiento, el Tribunal Constitucional invoca en apoyo de la excepción que menciona, el caso del requerimiento de inconstitucionalidad contra el Estatuto de Roma, conocido por la misma jurisdicción. ${ }^{6}$

Teniendo presente todas estas consideraciones anteriores, resulta interesante examinar la prevención del Ministro Navarro en el fallo relativo al control de constitucionalidad preventivo y obligatorio, de conformidad con el artículo $93 \mathrm{~N}^{\circ} 1$ de la Constitución, del Convenio $N^{\circ} 169$ sobre pueblos indígenas, adoptado por la Organización Internacional del Trabajo, de 27 de junio de 1989. ${ }^{7}$ En efecto, en dicho fallo, el Ministro Navarro afirma "que, según se dejó constancia en la historia fidedigna del establecimiento de esta norma, los preceptos contenidos en el Convenio $\mathrm{N}^{\circ} 169$, sobre pueblos indígenas y tribales en países independientes, no son autoejecutables, teniendo así el carácter de normas programáticas, que deberán ser desarrolladas por el legislador" ${ }^{8}$ Antes de examinar esta afirmación, es necesario tener presente que el referido Convenio $\mathrm{N}^{\circ} 169$ fue declarado constitucional -luego de un requerimiento de inconstitucionalidad-por sentencia del mismo Tribunal con fecha 4 de agosto de 2000. En consecuencia, siguiendo el razonamiento del Tribunal Constitucional precedentemente reseñado, sólo cabe pronunciarse sobre un tratado internacional cuando éste contiene normas autoejecutables, salvo que conteniendo normas no autoejecutables, el tratado pueda adolecer de vicios de inconstitucionalidad de fondo. Si el Tribunal Cons-

5 Tribunal Constitucional de Chile: Requerimiento formulado por Senadores para que se declare la inconstitucionalidad del proyecto de acuerdo que aprueba la Convención Interamericana sobre Desaparición Forzada de Personas, adoptada el 9 de junio de 1994 en Belén, Brasil, durante el XXIV Período Ordinario de Sesiones de la Asamblea General de la Organización de Estados Americanos. Rol N ${ }^{\circ}$ 383-2003. Sentencia de fecha 5 de septiembre de 2003. Considerando $4^{\circ}$, p. 11.

6 Tribunal Constitucional de Chile: Requerimiento respecto del Estatuto de Roma de la Corte Penal Internacional, adoptado en dicha ciudad el 17 de julio de 1998. Rol № 346-2002. Sentencia de fecha 8 de abril de 2002.

7 Tribunal Constitucional de Chile: Control de constitucionalidad del proyecto de acuerdo aprobatorio relativo al Convenio $N^{\circ} 169$ sobre pueblos indígenas, adoptado por la Organización Internacional del Trabajo, de 27 de junio de 1989. Rol N 1050-2008. Sentencia de fecha 3 de abril de 2008.

8 Tribunal Constitucional de Chile: Control de constitucionalidad del proyecto de acuerdo aprobatorio relativo al Convenio $N^{\circ} 169$ sobre pueblos indígenas, adoptado por la Organización Internacional del Trabajo, de 27 de junio de 1989. Rol № 1050-2008. Sentencia de fecha 3 de abril de 2008. Prevención Ministro Navarro. Considerando $1^{\circ}$, p. 11. 
titucional ya había señalado que el referido Convenio 169 no estaba afectado de vicios de inconstitucionalidad de fondo, y el Ministro señala que sus preceptos son no autoejecutables, ¿qué sentido tiene, por tanto, pronunciarse sobre las disposiciones del Convenio? Por otro lado, el Ministro invoca en apoyo de su tesis de la no autoejecutabilidad de los preceptos del Convenio 169, "la historia fidedigna del establecimiento de esta norma”, constitutiva del Informe de Gonzalo Arenas, Subsecretario del Ministerio de Planificación, el Informe del Ministro Secretario General de la Presidencia, señor José Antonio Viera-Gallo, y el Informe del Director Jurídico de la Cancillería. ${ }^{9}$ Estos pueden ser elementos de la historia fidedigna del Proyecto de Acuerdo aprobatorio del Convenio, pero no del establecimiento de la norma. La historia fidedigna del establecimiento de cualquier tratado internacional, de acuerdo con el Derecho Internacional, consta en los travaux préparatoires de los respectivos instrumentos. Ahora bien, la naturaleza de las disposiciones de un tratado depende de su contenido intrínseco, no de la calificación que de ellas hagan las partes, ni mucho menos una de las partes en sus procedimientos internos de incorporación del instrumento. En el caso del Convenio 169 , se trata de un instrumento internacional de derechos humanos que reconoce derechos fundamentales a los individuos y grupos respectivos, los cuales implican facultades que pueden ser directamente ejercidas por sus titulares en el orden interno e invocadas por esto ante los órganos jurisdiccionales chilenos, sin mayor intermediación normativa.

\section{B) Formalidades en la incorporación de los tratados internacionales}

Uno de los aspectos curiosos de esta sentencia es que, no obstante haberlo señalado en su argumentación a favor del control de constitucionalidad, el Tribunal Constitucional no se pronuncia sobre el vicio de fondo invocado por los requirentes. Y se esfuerza en dejarlo expresamente plasmado, cuando señala que "de la presente sentencia no puede deducirse, de manera alguna, que la circunstancia que este Tribunal considere, desde un punto de vista formal, que la norma del artículo IV, inciso segundo, del Tratado, incida en materias que caen bajo la órbita del artículo 74 de la Constitución, importaría una aceptación, implícita, de que los tribunales extranjeros, para conocer de delitos cometidos en Chile, se encuentran comprendidos entre las autoridades que la Carta Fundamental establece, porque ello implicaría, precisamente, un pronunciamiento sobre el fondo de la norma en estudio, resolución que este Tribunal no emite, ni debe emitir, constatada que sea una inconstitucionalidad formal”. De esta manera, como se verá a continuación, los jueces constitucionales se concentraron en examinar los aspectos de forma, esto es, fundamentalmente, por un lado, el examen previo de la inconstitucionalidad de forma y, por otro lado, el procedimiento parlamentario de aprobación de los tratados internacionales.

\footnotetext{
Tribunal Constitucional de Chile: Control de constitucionalidad del proyecto de acuerdo aprobatorio relativo al Convenio $N^{\circ} 169$ sobre pueblos indígenas, adoptado por la Organización Internacional del Trabajo, de 27 de junio de 1989. Rol N 1050-2008. Sentencia de fecha 3 de abril de 2008. Prevención Ministro Navarro. Considerando $2^{\circ}$, p. 11.
} 
a) Inconstitucionalidad de forma. Al mismo tiempo, el Tribunal Constitucional efectuó una distinción, no formulada por el requirente, en el sentido del examen de la constitucionalidad de forma y el examen de la constitucionalidad de fondo. Así el Tribunal Constitucional señaló, en el caso de la CIDFP, que "se considera indispensable efectuar una distinción, la cual es tan elemental y universalmente reconocida como esencial. En efecto, trátase de diferenciar la infracción a la Carta Fundamental de forma o procedimiento en que puede incurrir el órgano habilitado por ella para ejercer una potestad, de un lado, del quebrantamiento de fondo, material o sustantivo del Código Supremo en que ese órgano puede también incurrir, de otro. Evidentemente, la justificación de aquella diferencia yace en que, siendo transgresiones distintas, constatado que sea un vicio de forma en un precepto en tramitación, este ya no es tal y, por lo mismo, carece de todo sentido avanzar a su examen sustantivo o de fondo". ${ }^{10}$

En este sentido, los jueces constitucionales afirman que el control preventivo de constitucionalidad, para ser completo, debe abarcar tanto los aspectos de forma como aquellos sustanciales del proyecto de norma cuya constitucionalidad se objeta. De esta manera, el tribunal señaló que "por lo explicado y en cumplimiento, cabal y rigoroso, de la función de control preventivo de la supremacía de la Carta Política, esta Magistratura debe examinar, en primer lugar, si la norma cuyo mérito constitucional ha sido objetado en el requerimiento, fue o no generada, por los órganos competentes para ello, cumpliendo los trámites y con el quórum que la Ley Fundamental ha establecido a los efectos que se integre válidamente al régimen jurídico en vigor". ${ }^{11}$

A mayor abundamiento, el Tribunal Constitucional señaló sobre el examen de la inconstitucionalidad de forma y la inconstitucionalidad de fondo que "en la doctrina contemporánea, tanto nacional como extranjera, no existe discrepancia alguna en cuanto a distinguir entre la supremacía constitucional de forma, por un lado, y de fondo, de otro, siendo menester cumplir cuanto una y otra implican para que pueda considerarse válidamente gestada una disposición, sea ésta de índole legal, de un tratado internacional solemne o de jerarquía preceptiva inferior". ${ }^{2}$

10 Tribunal Constitucional de Chile: Requerimiento formulado por Senadores para que se declare la inconstitucionalidad del proyecto de acuerdo que aprueba la Convención Interamericana sobre Desaparición Forzada de Personas, adoptada el 9 de junio de 1994 en Belén, Brasil, durante el XXIV Período Ordinario de Sesiones de la Asamblea General de la Organización de Estados Americanos. Rol N 383-2003. Sentencia de fecha 5 de septiembre de 2003. Considerando $6^{\circ}$, p. 12.

11 Tribunal Constitucional de Chile: Requerimiento formulado por Senadores para que se declare la inconstitucionalidad del proyecto de acuerdo que aprueba la Convención Interamericana sobre Desaparición Forzada de Personas, adoptada el 9 de junio de 1994 en Belén, Brasil, durante el XXIV Período Ordinario de Sesiones de la Asamblea General de la Organización de Estados Americanos. Rol N ${ }^{\circ}$ 383-2003. Sentencia de fecha 5 de septiembre de 2003. Considerando $8^{\circ}$, p. 13.

12 Tribunal Constitucional de Chile: Requerimiento formulado por Senadores para que se declare la inconstitucionalidad del proyecto de acuerdo que aprueba la Convención Interamericana sobre Desaparición Forzada de Personas, adoptada el 9 de junio de 1994 en Belén, Brasil, durante el XXIV Período Ordinario de Sesiones de la Asamblea General de la Organización de Estados Americanos. Rol N ${ }^{\circ}$ 383-2003. Sentencia de fecha 5 de septiembre de 2003. Considerando $25^{\circ}$, pp. 19-20. 
b) Procedimiento de aprobación de tratados. Desde la perspectiva del procedimiento interno de aprobación de los tratados, en el caso de la CIDFP, el Tribunal Constitucional hizo una afirmación que se ha visto actualizada conforme a la Reforma Constitucional del año 2005. En efecto, el Tribunal Constitucional señaló que la Constitución contemplaba un conjunto de disposiciones y principios en materia de proceso de formación de la ley que era armonioso y coherente y que este conjunto de principios se aplicaba con igual valor al proceso de aprobación de los proyectos de acuerdos sobre los tratados ante el Congreso Nacional. En este sentido, el Tribunal Constitucional afirma que "así se desprende, en términos inequívocos, del artículo 50, número 1 , inciso primero, de la Constitución, precepto en el cual consta, con lenguaje de significado imperativo, que '[l]a aprobación de un tratado se someterá a los trámites de una ley". Como se sabe, esta disposición fue modificada a través de la Reforma Constitucional del año 2005 -publicada en el Diario Oficial el 26 de agosto de 2005-, por la que se encuentra actualmente contenida en el artículo 54 número 1, inciso 1, que reza como sigue: "La aprobación de un tratado requerirá, en cada Cámara, de los quórum que corresponda, en conformidad al artículo 66, y se someterá, en lo pertinente, a los trámites de una ley”. En consecuencia, como se verá, en esta materia, la Reforma Constitucional acogió la doctrina consagrada por el Tribunal Constitucional en el requerimiento de inconstitucionalidad respecto de la CIDFP y en otras sentencias referidas a tratados internacionales, como la que se pronunció sobre el Convenio $N^{\circ} 169$, Sobre Pueblos Indígenas y Tribales en Países Independientes, adoptado por la Organización Internacional del Trabajo, el 27 de junio de 1989.

Desde el punto de vista del procedimiento de aprobación de los Proyectos de acuerdo sobre tratados internacionales, el Tribunal Constitucional chileno señaló, en el caso sobre la CIDFPy apoyándose en lo afirmado en el caso del Convenio $N^{\circ} 169$, que "interpretando ambas normas constitucionales de forma razonable, fuerza es concluir que las disposiciones del tratado en el caso que este contemple normas de distinta naturaleza se aprobarán o rechazarán aplicando el quórum que corresponde a los distintos grupos de ellas; pero el proyecto de acuerdo de aprobación del tratado sólo se entenderá sancionado por la respectiva Cámara Legislativa cuando todas las disposiciones del tratado hubiesen sido aprobadas en ella. En caso que una o más disposiciones de la respectiva Convención fuere desestimada, el proyecto de acuerdo debe entenderse rechazado como un todo". ${ }^{13}$

¿Cuáles son las formalidades que la Constitución impone en texto expreso y de modo inequívoco como requisitos esenciales para la validez y constitucionalidad de

13 Tribunal Constitucional de Chile: Requerimiento respecto del Convenio $N^{\circ} 169$, Sobre Pueblos Indígenas y Tribales en Países Independientes, adoptado por la Organización Internacional del Trabajo, el 27 de junio de 1989. Rol N ${ }^{\circ}$ 309-2000. Sentencia de fecha 4 de agosto de 2000. Considerando $25^{\circ}$; Tribunal Constitucional de Chile: Requerimiento formulado por Senadores para que se declare la inconstitucionalidad del proyecto de acuerdo que aprueba la Convención Interamericana sobre Desaparición Forzada de Personas, adoptada el 9 de junio de 1994 en Belén, Brasil, durante el XXIV Período Ordinario de Sesiones de la Asamblea General de la Organización de Estados Americanos. Rol N 383-2003. Sentencia de fecha 5 de septiembre de 2003. Considerando $14^{\circ}$, p. 19. 
las actuaciones de los órganos estatales encargados de aprobar los proyectos de acuerdo sobre tratados internacionales? El Tribunal Constitucional se encargó de precisarlos, en el caso sobre la CIDFP, al señalar las siguientes: “A. Lo previsto en el artículo 63, inciso segundo, de la Constitución, es decir, la reunión del quórum de 4/7 de los diputados y senadores en ejercicio para la aprobación de ese proyecto de Acuerdo en relación con la Convención a la cual él se refiere; y B. La caracterización de las leyes orgánicas constitucionales, y de los preceptos de esa misma naturaleza, hecha por este Tribunal Constitucional, principalmente en sus sentencias de 26 de noviembre y 22 de diciembre, ambas de 1981 (Roles Nos 4 y 7, respectivamente). De esa jurisprudencia fluye que las normas de las leyes orgánicas constitucionales deben reunir, en lo atinente al caso sub lite, entre otras, las características siguientes: contar con el quórum fijado en el artículo 63, inciso segundo, de la Carta Fundamental; y no efectuar la delegación de facultades legislativas donde el Código Político ha reservado la regulación de un asunto a tal clase de preceptos legales". ${ }^{14}$ Además, cabría agregar que el propio Tribunal Constitucional ha complementado estas exigencias formales en el sentido de que no es causal de inconstitucionalidad de forma del Proyecto de Acuerdo cuando se calificó mal la materia del Convenio -es decir, se indicó que se trata de materias de ley ordinaria en circunstancias que en realidad eran materias propias de ley orgánica- siempre que, de facto, se haya reunido un quórum de aprobación de ley orgánica constitucional. En efecto, en el caso del Requerimiento respecto del tratado entre la República de Chile y la República de Argentina sobre integración y complementación minera, el Tribunal Constitucional señaló que "el error en que se incurrió durante la tramitación de su aprobación en la Cámara de Diputados, al calificar como de ley simple materias propias de leyes orgánicas, queda desprovisto de la trascendencia indispensable para declararlo inconstitucional, por cuanto el quórum de votación excede el mínimo exigido por el inciso segundo del ya mencionado artículo 63. Al efecto, en fecha reciente, al resolver un caso similar, este Tribunal expresó que '[...] no resulta ni razonable ni prudente que tal error autorice para declarar la inconstitucionalidad de forma del acuerdo aprobatorio del convenio cuestionado, pues desde un punto de vista material se cumplió con el fin perseguido por la señalada norma constitucional'. Que en tal evento, las supuestas modificaciones, por tener el respaldo de los quórum pertinentes, no merecerían reproche desde el punto de vista constitucional". ${ }^{15}$

En el caso de la CIDFP, el Tribunal Constitucional acogió el requerimiento porque no se aprobó el Proyecto de Acuerdo sobre la Convención con los quórum que corres-

14 Tribunal Constitucional de Chile: Requerimiento formulado por Senadores para que se declare la inconstitucionalidad del proyecto de acuerdo que aprueba la Convención Interamericana sobre Desaparición Forzada de Personas, adoptada el 9 de junio de 1994 en Belén, Brasil, durante el XXIV Período Ordinario de Sesiones de la Asamblea General de la Organización de Estados Americanos. Rol № 383-2003. Sentencia de fecha 5 de septiembre de 2003. Considerando $17^{\circ}$, p. 20.

15 Tribunal Constitucional: Requerimiento respecto del tratado entre la República de Chile y la República de Argentina sobre integración y complementación minera. Rol 312-2000. Sentencia de fecha 3 de octubre del 2000. Considerandos $6^{\circ}$ y $7^{\circ}$, p. 13; Tribunal Constitucional de Chile: Requerimiento respecto del Convenio $N^{\circ} 169$, Sobre Pueblos Indígenas y Tribales en Países Independientes, adoptado por la Organización Internacional del Trabajo, el 27 de junio de 1989. Rol № 309-2000. Sentencia de fecha 4 de agosto de 2000 . Considerando $30^{\circ}$. 
pondían de acuerdo a la materia de que se trataba y en conformidad a lo dispuesto en la propia Constitución, pero además, declaró la inconstitucionalidad de la propia Convención. En efecto, los jueces constitucionales señalaron que "[t]al secuela, ya demostrada, en general, en los considerandos anteriores de esta sentencia, aquí consiste en que el Proyecto de Acuerdo y la Convención a la cual aquél se refiere, no fueron aprobados, en la Cámara de Diputados, con el quórum que la Constitución exige. Esta razón es suficiente, por lo explicado, para concluir, desde el ángulo estrictamente formal, que uno y otra infringen la Carta Fundamental y que debe ser así declarado". ${ }^{16}$ Esta última declaración resulta bastante curiosa, por cuanto el Tribunal Constitucional nunca entró a pronunciarse sobre el fondo del requerimiento y lo excluyó expresamente. En nuestra opinión, una cosa es la inconstitucionalidad del proyecto de Acuerdo, por cuanto el acuerdo no recabó los quórum requeridos por la Constitución y otra cosa es la inconstitucionalidad de la Convención, es decir, del tratado internacional en sí mismo considerado. Sin embargo, en este caso, el Tribunal Constitucional parece asimilar ambas situaciones. ${ }^{17}$

Como se ha dicho, la doctrina afirmada por el Tribunal Constitucional a propósito del procedimiento interno de aprobación de tratados internacionales ha sido incorporada a la Constitución en la Reforma del año 2005. En este sentido, esta Reforma ha permitido aclarar en la Constitución dos aspectos cruciales en materia de tratados internacionales, a saber, por un lado la naturaleza de los tratados internacionales en el orden interno y, por otro lado, el rango jerárquico de los tratados internacionales en el orden interno.

i) Naturaleza de los tratados internacionales en el orden interno. En una época anterior a la Reforma Constitucional del año 2005, los tratados internacionales incorporados -a través del procedimiento constitucional previsto al efecto- al ordenamiento jurídico interno chileno, eran considerados, desde la perspectiva de su naturaleza, como leyes.

16 Tribunal Constitucional de Chile: Requerimiento formulado por Senadores para que se declare la inconstitucionalidad del proyecto de acuerdo que aprueba la Convención Interamericana sobre Desaparición Forzada de Personas, adoptada el 9 de junio de 1994 en Belén, Brasil, durante el XXIV Período Ordinario de Sesiones de la Asamblea General de la Organización de Estados Americanos. Rol N 383-2003. Sentencia de fecha 5 de septiembre de 2003. Considerando $20^{\circ}$, p. 22.

17 "Que habiéndose demostrado que una norma de la Convención en estudio, tiene, a lo menos, el rango propio de ley orgánica constitucional y que en su tramitación no se cumplió con el quórum requerido por el artículo 63, inciso segundo, de la Carta Fundamental, en una de las Cámaras Legislativas, procede que el proyecto de acuerdo aprobatorio y el Tratado sean declarados inconstitucionales, por vicio de forma, en su integridad”. Tribunal Constitucional de Chile: Requerimiento formulado por Senadores para que se declare la inconstitucionalidad del proyecto de acuerdo que aprueba la Convención Interamericana sobre Desaparición Forzada de Personas, adoptada el 9 de junio de 1994 en Belén, Brasil, durante el XXIV Período Ordinario de Sesiones de la Asamblea General de la Organización de Estados Americanos. Rol N ${ }^{\circ}$ 383-2003. Sentencia de fecha 5 de septiembre de 2003. Considerando $21^{\circ}$, p. 22. 
Con posterioridad a la Reforma Constitucional del año 2005, ha quedado claramente establecido que los tratados internacionales incorporados en el orden interno, poseen justamente esa calidad y naturaleza, son tratados internacionales, es decir, acuerdo de voluntades entre sujetos de Derecho Internacional y regulado por este mismo ordenamiento jurídico. En consecuencia, desde la perspectiva constitucional chilena, los tratados internacionales no son ni pueden ser considerados para ningún efecto, leyes. Por el contrario, los tratados internacionales son normas de carácter internacional que nace, vive y muere conforme al ordenamiento que le dio origen, esto es, el Derecho Internacional.

El artículo $54 \mathrm{~N}^{\circ} 1$ de la Constitución actualmente señala que "[l]a aprobación de un tratado requerirá, en cada Cámara, de los quórum que corresponda, en conformidad al artículo 66, y se someterá, en lo pertinente, a los trámites de una ley”. El artículo $50 \mathrm{~N}^{\circ} 1$ anterior, señalaba que "[l]a aprobación de un tratado se someterá a los trámites de una ley". La expresión "en lo pertinente" vino a reforzar la idea de que los tratados internacionales no tienen el carácter de ley.

El principio anterior se ve reiterado en el mismo artículo $54 \mathrm{~N}^{\circ} 1$ inciso $5^{\circ}$, cuando señala "[l]as disposiciones de un tratado sólo podrán ser derogadas, modificadas o suspendidas en la forma prevista en los propios tratados o de acuerdo a las normas generales de derecho internacional". Hay otras disposiciones constitucionales que refuerzan este principio, como por ejemplo, aquella que se refiere a la denuncia de un tratado, cuando señala que "[u]na vez que la denuncia o el retiro produzca sus efectos en conformidad a lo establecido en el tratado internacional, éste dejará de tener efecto en el orden jurídico chileno". ${ }^{18}$

Un pronunciamiento en este mismo orden de cosas ha efectuado la Corte Suprema en el caso por el secuestro calificado de Troncoso Muñoz y otros, cuando ha señalado que "la obligación estatal que dimana de la Constitución, de los Tratados Internacionales sobre Derechos Humanos y de los Principios Generales de Derecho Internacional Humanitario, existía bajo nuestra Carta Fundamental de mil novecientos veinticinco, pues Chile al igual que hoy era un Estado Constitucional de Derecho, y le era exigible la congruencia de aquélla con los aludidos acuerdos multilaterales y axiomas. Por lo que el legislador no tiene atribución alguna para modificar por ley un acuerdo internacional y si bien podría dictarla, prescribiendo disposiciones contrarias a este o que hiciesen imposible su cumplimiento, ese acto del órgano legislativo comportaría una contravención al ordenamiento internacional. No puede ser de otra manera, en especial respecto de los tratados en materia de derechos humanos, ya que "éstos tienen una naturaleza distinta de la ley, en la medida en que no son actos jurídicos unilaterales, sino actos jurídicos bi o multilaterales en que intervienen las voluntades de diversos Estados. Además, estos tratados se constituyen no en beneficio de los Estados parte sino en resguardo de la dignidad y los derechos inherentes al ser humano por el

18 Vid. Artículo $50 \mathrm{~N}^{\circ} 1$ inciso $1^{\circ}$. 
solo hecho de ser persona. Los Estados parte por tal reconocimiento constituyen una autolimitación a su soberanía. No pueden, por ende, desvincularse unilateralmente de los tratados en materia de derechos humanos, sino de acuerdo al procedimiento establecido en ellos mismos". Un acuerdo internacional, por consiguiente, no puede dejar de aplicarse sino de conformidad con las normas de derecho internacional". ${ }^{19}$

ii) Rango jerárquico de los tratados internacionales en el orden interno. La Reforma Constitucional del año 2005 también ha operado una aclaración relevante desde la perspectiva de la jerarquía de los tratados internacionales incorporados -a través del procedimiento constitucional previsto al efecto- al ordenamiento jurídico interno chileno.

Con anterioridad a la Reforma del año 2005, el criterio sostenido, aunque criticado, era que los tratados internacionales tenían el carácter de leyes, jerarquía de leyes y, consecuentemente, estaban sujetos a la supremacía constitucional. Esta conclusión no variaba en el caso de los tratados internacionales de derechos humanos. Una muestra de este criterio se puede encontrar en el fallo del Tribunal Constitucional relativo al Estatuto de Roma, de fecha 8 de abril de 2002. ${ }^{20}$

La Reforma Constitucional del año 2005 ha modificado esta relación de fuerzas. Así, como se ha dicho precedentemente, los tratados internacionales no son leyes, y al no ser leyes no pueden ser modificados o dejados sin efecto por una norma de este carácter, que tiene su origen en el órgano legislativo del Estado. En consecuencia, en el evento de conflicto entre normas legales y normas internacionales convencionales debe primar esta última. En adición al principio anterior debe tenerse presente que el Estado se encuentra obligado por el Derecho Internacional a adecuar su orden jurídico interno a las normas de ese ordenamiento.

Por tanto, la discusión y debate, hoy se centra en si los tratados internacionales tienen un rango supraconstitucional, constitucional o infraconstitucional, pero supralegal, sin perjuicio del debate particular a propósito de los tratados de derechos humanos, los cuales tienen un antecedente adicional en el artículo 5 inciso $2^{\circ}$ de la Constitución chilena, que refuerza la posición por la jerarquía constitucional de dichos tratados.

En primer lugar, hay dos argumentos que pueden sostenerse para negar lugar al rango constitucional de los tratados internacionales y son, por un lado, el control de

19 Corte Suprema: Caso sobre el secuestro calificado de Troncoso Muñoz, Ricardo Aurelio y otros. Rol $\mathrm{N}^{\circ}$ 3452-2006. Sentencia de fecha 10 de mayo de 2007. Considerando $65^{\circ}$.

20 "Que, con anterioridad a la reforma de 1989, había opinión unánime en el sentido que los tratados internacionales estaban sujetos al principio de supremacía constitucional". "Que, en este aspecto, es relevante recordar que, aunque aparezca obvio, la norma constitucional reformada no consagró que los tratados internacionales sobre derechos esenciales tuvieran una jerarquía igual o superior a la Ley Fundamental". Tribunal Constitucional de Chile: Requerimiento respecto del Estatuto de Roma de la Corte Penal Internacional, adoptado en dicha ciudad el 17 de julio de 1998 . Rol № 346-2002. Sentencia de fecha 8 de abril de 2002 . Considerandos $61^{\circ}$ y $62^{\circ}$. 
constitucionalidad de los mismos, y por otro lado, aceptar la jerarquía constitucional de un tratado puede significar admitir la posibilidad de introducir una Reforma a la Constitución por una vía no prevista en la misma Constitución de 1980, que contempla un sistema rígido de Reforma Constitucional. ${ }^{21}$

En segundo lugar, en este contexto, el control de constitucionalidad se refiere a una de las fuentes del Derecho Internacional, esto es, a los tratados internacionales, no a los derechos en sí mismo considerados, a los derechos incorporados en estos tratados. Ahora bien, desde el punto de vista de los tratados de derechos humanos, puede tener sentido declarar un tratado (continente) contrario a la Constitución y, luego, afirmar que los derechos fundamentales (su contenido) son superiores a toda norma del orden jurídico interno y que limitan la soberanía del Estado, incluido el propio poder constituyente. En mi opinión, ello sólo demostraría que los derechos tienen vigencia bajo la forma de derecho consuetudinario y de principios generales.

Sin embargo, desde un punto de vista más general, hay que tomar en cuenta otra consideración, esto es, el hecho de que, desde la perspectiva internacional, el Derecho Internacional tiene primacía por sobre el derecho interno, incluso por sobre la Constitución..$^{22}$ En efecto, el derecho interno se encuentra inserto en un sistema internacional globalizado, integrado e interdependiente, por lo tanto, le corresponde a esta parte -el orden interno- respecto del todo -el orden internacional-, sujetarse a los patrones y parámetros consensuados y acordados en el orden internacional, en virtud de un principio de coherencia y armonía. Consecuentemente, desde la perspectiva chilena, más que un control de constitucionalidad, al estilo del control de constitucionalidad de las leyes, el Tribunal Constitucional efectúa una verificación de la adecuación de la Constitución a la norma internacional, disponiendo si es necesario, para efectos de incorporar la referida norma internacional, adecuar la Constitución a lo dispuesto por la Convención o Tratado. En este sentido, se podría pensar que un Tratado no es contrario a la Constitución sino que la Constitución es contraria a un tratado, razón por la cual se requiere la modificación de la Constitución, idea que es reconocida por el Tribunal Constitucional en varios pasajes de su sentencia en el caso de la CIDFP.

No se trata de un caso de control de constitucionalidad tradicional, es un caso de control de la adecuación de la Constitución al Derecho Internacional y, en caso de oposición, dispone la modificación y adecuación del derecho interno al Derecho Inter-

21 Tribunal Constitucional de Chile: Requerimiento respecto del Estatuto de Roma de la Corte Penal Internacional, adoptado en dicha ciudad el 17 de julio de 1998. Rol No 346-2002. Sentencia de fecha 8 de abril de 2002. Considerandos $68^{\circ}$; Vid. Capítulo XV: Reforma de la Constitución. Constitución Política de la República de Chile de 1980.

22 "27. El derecho interno y la observancia de los tratados. Una parte no podrá invocar las disposiciones de su derecho interno como justificación del incumplimiento de un tratado". Convención de Viena sobre el derecho de los tratados. Adoptada en Viena, el 23 de mayo de 1969. U.N. Doc A/CONF.39/ 27 (1969), 1155 U.N.T.S. 331, entered into force January 27, 1980. 
nacional. ${ }^{23}$ El control de constitucionalidad de la ley, en caso de inconstitucionalidad, afecta la existencia misma de la norma, afecta su vida, la ley no nace a la vida, o, si ha nacido, la norma es declarada inaplicable o es expulsada del ordenamiento. En cambio, el control de constitucionalidad de fondo del tratado, en caso de necesitar la adecuación de la Constitución, dicha declaración no afecta la existencia misma de la norma internacional, del tratado o convención, sólo queda en compás de espera de la adecuación -adecuación que constituye una obligación internacional del Estado- para poder incorporar armoniosamente la referida disposición internacional. Esto último demuestra que la norma internacional no tiene un rango inferior a la Constitución, sino más bien, tendrían una jerarquía, a lo menos, equivalente a la Constitución, lo cual es de tal manera importante que ello obliga al Estado a adecuar su Constitución al Tratado o Convención, para la incorporación del mismo, es decir, el Derecho Internacional provoca, en el proceso de incorporación, la reforma constitucional ¿qué mejor prueba de la jerarquía de los tratados?

En consecuencia, en virtud de lo dispuesto en el artículo $5^{\circ}$ de la Constitución, los tratados internacionales de derechos humanos son de rango constitucional. Además, los tratados internacionales de derechos humanos tendrían rango constitucional. Y desde el punto de vista del derecho material, los derechos humanos, cuya existencia se apoya en la generación de normas consuetudinarias y de principios generales, son supraconstitucionales. Existe una jurisprudencia reiterada y constante sobre este último punto. ${ }^{24}$

23 "Que, este criterio que implica que una jurisdicción supranacional como la Corte Penal Internacional no pueda integrarse al ordenamiento jurídico nacional, frente a los claros términos de nuestra Constitución, y sin entrar al mérito del Tratado, no significa que frente a los crímenes atroces que presenció la humanidad en el siglo XX, se acepte la impunidad. Por el contrario, el mundo ve hoy la necesidad de enjuiciar y sancionar en su caso, esos delitos, pero una jurisdicción de carácter supranacional debe insertarse dentro del sistema constitucional nacional procediendo previamente a modificar el texto de la Constitución". Tribunal Constitucional de Chile: Requerimiento respecto del Estatuto de Roma de la Corte Penal Internacional, adoptado en dicha ciudad el 17 de julio de 1998. Rol № 346-2002. Sentencia de fecha 8 de abril de 2002. Considerando $92^{\circ}$, p. 118; "La Presidente subrogante Ministro señora Luz Bulnes Aldunate, concurre al fallo en el entendido que los artículos $5^{\circ}, 18,19$ y 20 del Tratado no crean un tribunal con facultades jurisdiccionales". (...) "Si así no fuera, se trataría de un tribunal internacional al que se le habría delegado soberanía y sus resoluciones obligarían al Estado de Chile. Para ello sería menester que se reformaran los artículos $5^{\circ}, 73$ y 79 de la Constitución Política”. Tribunal Constitucional de Chile: Requerimiento respecto del tratado entre la República de Chile y la República de Argentina sobre integración y complementación minera. Rol $N^{\circ} 312-2000$. Sentencia de fecha 3 de octubre de 2000. Voto concurrente Ministra Luz Bulnes Aldunate, p. 26.

24 Tribunal Constitucional de Chile. Requerimiento de inaplicabilidad por inconstitucionalidad presentado por Luis Carlos Valdés Correa en relación al artículo 2.331 del Código Civil, en causa Rol N 2429-2007 caratulada "Valdés con Jaime Irarrázabal Covarrubias y otros", del Décimo Octavo Juzgado Civil de Santiago. Rol N ${ }^{\circ}$ 943-2008. Sentencia de fecha 10 de junio de 2008. Considerando $16^{\circ}$, p. 17. 


\section{III \\ LO QUE NO DIJO: LA DESAPARICIÓN FORZADA DE PERSONAS Y EL PRINCIPIO DE JURISDICCIÓN UNIVERSAL}

Tal como el mismo Tribunal Constitucional afirmó en su sentencia sobre la CIDFP, los senadores solicitaron a los jueces constitucionales que "declare inconstitucional el Proyecto de Acuerdo que aprueba la Convención Interamericana sobre Desaparición Forzada de Personas, porque la consagración del principio de Universalidad de Jurisdicción, expresamente reconocido por el Ejecutivo en el Mensaje y establecido, con precisión, en el inciso segundo del artículo IV de la Convención, es contraria a los artículos 5, 6, 7, $19 \mathrm{~N}^{\circ}$ 3, 73, 74 y 79 de la Carta Fundamental”. ${ }^{25}$

Como se ha dicho, el Tribunal Constitucional no se pronunció sobre este punto ya que constató previamente una inconstitucionalidad formal del proyecto de Acuerdo. Sin embargo, vale la pena hacer algunas reflexiones a este propósito, que, eventualmente, una vez reunidos los quórum necesarios para adoptar los acuerdos, pueden ser tenidos en cuenta por el Tribunal para evaluar posibles argumentaciones de inconstitucionalidad de fondo, como las expresadas en el párrafo precedente.

En primer término, el requirente señala que el principio de jurisdicción universal "obliga a todo Estado parte a someter a un delincuente que se encuentre dentro de su territorio a la jurisdicción propia, aun cuando el delito de desaparición forzada de personas se hubiere cometido en territorio de otro Estado, lo que implica reconocer competencia a tribunales extranjeros sobre hechos constitutivos de delito ocurridos en Chile". Sólo que aquí no estamos hablando ni de robos, hurtos o fraudes, estamos frente a hechos que configuran atrocidades y que atacan el corazón de la dignidad humana como bien esencial de la comunidad internacional. En este sentido, todos los Estados, a través de su función jurisdiccional, están obligados a investigar, juzgar y sancionar adecuadamente los crímenes internacionales y esta obligación emana de los principios generales y del Derecho Internacional consuetudinario. En efecto, la Corte Suprema ha sostenido en este sentido que "[e]ste colofón, es el único posible aún ante la inexistencia de derecho convencional en la materia, pues la consideración de los hechos como crímenes de lesa humanidad genera en cada Estado miembro de la comunidad internacional la obligación de juzgar y castigar a sus autores, en tanto delitos lesionadores de valores que la humanidad no duda en calificar como esenciales y constitutivos de la persona" ${ }^{26}$ En consecuencia, para estos efectos, es irrelevante

25 Tribunal Constitucional de Chile: Requerimiento formulado por Senadores para que se declare la inconstitucionalidad del proyecto de acuerdo que aprueba la Convención Interamericana sobre Desaparición Forzada de Personas, adoptada el 9 de junio de 1994 en Belén, Brasil, durante el XXIV Período Ordinario de Sesiones de la Asamblea General de la Organización de Estados Americanos. Rol N 383-2003. Sentencia de fecha 5 de septiembre de 2003. Considerando $1^{\circ}$, p. 10.

26 Corte Suprema: Caso sobre el secuestro calificado de Troncoso Muñoz, Ricardo Aurelio y otros. Rol $\mathrm{N}^{\circ}$ 3452-2006. Sentencia de fecha 10 de mayo de 2007. Considerando $65^{\circ}$. 
que un Estado, por vía de su Constitución, reconozca o no el principio de jurisdicción universal, y, además, no es necesario que la Constitución reconozca el principio para estar obligado por el Derecho Internacional. Por lo demás, como el propio Tribunal Constitucional lo ha señalado en el caso de la CIDFP, la regla que refleja el principio de jurisdicción universal es una norma directamente aplicable o autoejecutable. ${ }^{27}$

En segundo término, el requirente alegó que "al otorgarse a un tribunal extranjero atribuciones para conocer de delitos ocurridos dentro del territorio de la República, se está reconociendo potestad jurisdiccional a una autoridad no establecida por la Carta Fundamental, lo que constituye una violación de dicho precepto constitucional (artículo $5^{\circ}$ inciso primero)". Nuevamente, aquí hay que reiterar que no se está otorgando potestad jurisdiccional a un tribunal extranjero, justamente, en virtud del Derecho Internacional, estos tribunales -todas las jurisdicciones de los Estados- son competentes para perseguir penalmente a los responsables de crímenes contra la humanidad. Con norma convencional o sin norma convencional, el Estado se encuentra obligado por el Derecho Internacional. Desde nuestro punto de vista, según estas argumentaciones del requirente no se puede entender cómo se aceptó y Chile se sometió a la jurisdicción de la Corte Interamericana de Derechos Humanos, y, en su momento, no se impugnó dicho sometimiento como inconstitucional.

En tercer término, los requirentes argumentan que "la potestad jurisdiccional, le permite a los tribunales conocer, resolver y hacer ejecutar lo juzgado, excluyendo, respecto de los conflictos sometidos a su decisión, cualquier injerencia de autoridad alguna , sea nacional o internacional" y agregan que el tratado internacional en cuestión altera esta situación. Al contrario de la señalado por los requirentes, lo que hace la Convención es afirmar este principio, por cuanto, en primer lugar le corresponde primordialmente a los tribunales del foro doméstico iniciar la investigación y juzgamiento de los responsables de la desaparición forzada. Pero si estos tribunales domésticos no quieren o no pueden, con el objeto de evitar la impunidad, cualquier tribunal de otro Estado es competente perseguir a los responsables.

27 "[...] pues el artículo IV, inciso segundo, de la Convención en estudio, no puede calificarse como una norma no autoejecutable, por la consecuencia especial que deriva de su aplicación, de conformidad a sus propios términos. En efecto, el precepto aludido cobra plena eficacia, y se basta a sí mismo, ratificado que sea por Chile el Tratado, ya que cualquier Estado Parte de él que lo haya incorporado a su ordenamiento jurídico interno y hubiese ajustado su legislación, tendrá jurisdicción para juzgar a un chileno por actos cometidos en Chile que configuren el delito de desaparición forzada de personas, bastando para ello que no proceda extraditarlo, independientemente de si Chile adecuó o no su propia legislación". Tribunal Constitucional de Chile: Requerimiento formulado por Senadores para que se declare la inconstitucionalidad del proyecto de acuerdo que aprueba la Convención Interamericana sobre Desaparición Forzada de Personas, adoptada el 9 de junio de 1994 en Belén, Brasil, durante el XXIV Período Ordinario de Sesiones de la Asamblea General de la Organización de Estados Americanos. Rol $N^{\circ} 383-2003$. Sentencia de fecha 5 de septiembre de 2003 . Considerando $3^{\circ}$, p. 11 
En cuarto término, los senadores esgrimen que la Corte Suprema tiene la superintendencia directiva, correccional y económica sobre todos los tribunales de la Nación. En este caso, aquellos a los que se refiere el artículo IV de la convención quedarían excluidos, lo que debe quedar plasmado en la Constitución. ¿Cómo podría lógicamente comprenderse que la Corte Suprema chilena tuviera dicha superintendencia sobre tribunales extranjeros?

Finalmente, los requirentes afirman que "la jurisdicción corresponde ejercerla a los tribunales establecidos por la ley chilena”. El artículo IV de la Convención altera esta situación de modo que habría que modificar la Constitución. Esta afirmación se refiere al principio de legalidad en lo relativo a que una persona sólo puede ser juzgada por tribunales establecidos por la ley en forma previa. Esto último se ve complementado tratándose de crímenes internacionales, cuyo estatuto jurídico proviene del Derecho Internacional y no del Derecho nacional, en donde los tribunales competentes, según el Derecho Internacional, son todos los tribunales de los Estados miembros de la comunidad internacional. Esta es la única manera de entender el principio de jurisdicción universal, pensado para crímenes internacionales, no para crímenes comunes, donde la constitucionalidad y legalidad orgánica jurisdiccional operan plenamente. En consecuencia, a los tribunales chilenos establecidos en forma previa en la ley les corresponden primeramente el juzgamiento de los responsables de desapariciones forzadas, pero si ellos no quieren o no pueden, entonces, con el fin de evitar que el hecho y el responsable queden en la impunidad, le corresponde a cualquier otro tribunal su juzgamiento.

Estas argumentaciones de inconstitucionalidad planteadas por los Senadores pueden ser contrarrestadas si se tiene presente una serie de consideraciones que provienen del Derecho Internacional y que se refieren, por un lado, a la naturaleza de la obligación y, por otro lado, a los compromisos internacionales de Chile, las cuales se analizarán en forma sucesiva, respectivamente.

\section{IV LA NATURALEZA DE LA OBLIGACIÓN}

En primer lugar, la CIDFP representa la codificación de normas que se encuentran reconocidamente formando parte del Derecho Internacional consuetudinario. Así lo ha demostrado, como se verá más adelante, una serie de decisiones jurisprudenciales emanadas tanto de tribunales nacionales como de tribunales internacionales en esta materia. Esta codificación del Derecho Internacional consuetudinario se ha producido, inter alia, a través de los siguientes instrumentos:

1. La Declaración sobre la protección de todas las personas contra las desapariciones forzadas, que señala en su preámbulo que "las desapariciones forzadas afectan los valores más profundos de toda sociedad respetuosa de la primacía del derecho, de los 
derechos humanos y de las libertades fundamentales, y que su práctica sistemática representa un crimen de lesa humanidad". ${ }^{28}$

2. La Convención Interamericana sobre Desaparición Forzada de Personas. Esta Convención tiene como objetivos y fin del tratado, contemplados en el Preámbulo, la afirmación de que "la desaparición forzada de personas viola múltiples derechos esenciales de la persona humana de carácter inderogable, tal como están consagrados en la Convención Americana sobre Derechos Humanos, en la Declaración Americana de los Derechos y Deberes del Hombre y en la Declaración Universal de Derechos Humano". ${ }^{29}$ Además, desde la perspectiva jurisdiccional, el Preámbulo recuerda "que la protección internacional de los derechos humanos es de naturaleza convencional coadyuvante o complementaria de la que ofrece el derecho interno y tiene como fundamento los atributos de la persona humana”. Y finalmente, el Preámbulo, vuelve a afirmar que "la práctica sistemática de la desaparición forzada de personas constituye un crimen de lesa humanidad”.

3. La Convención Internacional para la protección de todas las personas contra las desapariciones forzadas, que dispone en su artículo $5^{\circ}$ que "[l]a práctica generalizada o sistemática de la desaparición forzada constituye un crimen de lesa humanidad tal como está definido en el derecho internacional aplicable y entraña las consecuencias previstas por el derecho internacional aplicable". Por su parte, los artículos 9, 10 y 11 establecen el principio de jurisdicción universal. ${ }^{30}$

Esta consideración es de la máxima importancia, porque si bien la CIDFP y, además, la Convención Internacional para la protección de todas las personas contra las desapariciones forzadas, no han sido aprobadas internamente a través del proceso constitucional respectivo, esto afecta únicamente la vigencia interna de las normas convencionales sobre desaparición forzada de personas. De esta manera, las normas internacionales convencionales sobre desaparición forzada de personas, tienen plena vigencia internacional, de acuerdo con las disposiciones de dicho ordenamiento. Además, las normas consuetudinarias sobre desaparición forzada de personas permanecen absolutamente vigentes y, desde el punto de vista del orden jurídico interno, son de incorporación automática.

28 Declaración sobre la protección de todas las personas contra las desapariciones forzadas. Aprobada por la Asamblea General de las Naciones Unidas en su resolución 47/133 de 18 de diciembre 1992.

29 Convención Interamericana sobre Desaparición Forzada de Personas. Adoptada en Belém do Pará, Brasil el 9 de junio de 1994, en el vigésimo cuarto período ordinario de sesiones de la Asamblea General de la Organización de Estados Americanos y firmada por nuestro país el 6 de octubre de 1994.

30 Convención Internacional para la protección de todas las personas contra las desapariciones forzadas. Aprobada y abierta a la firma por la Asamblea General en su $82^{a}$ sesión plenaria, de fecha 20 de diciembre de 2006 y suscrita por Chile el 6 de febrero de 2007. Doc. A/RES/61/177, de fecha 12 de enero de 2007. 
En segundo lugar, la desaparición forzada de personas, como crimen internacional, forma parte del dominio de las normas de ius cogens. Así ha sido afirmado, entre otros, por la Corte IDH, al aseverar que "la Corte estima que, tal como se desprende del preámbulo de la Convención Interamericana sobre Desaparición Forzada de Personas (sic), ante la particular gravedad de estos delitos y la naturaleza de los derechos lesionados, la prohibición de la desaparición forzada de personas y el correlativo deber de investigarlas y sancionar a sus responsables han alcanzado carácter de jus cogens". ${ }^{31}$ En consecuencia, la norma que prohíbe la desaparición forzada de personas es de suprema jerarquía, absoluta e inderogable, donde la voluntad estatal no puede jugar ningún rol. En este sentido y a mayor abundamiento, el Preámbulo de la Convención Interamericana sobre Desaparición Forzada de Personas destaca "que la desaparición forzada de personas viola múltiples derechos esenciales de la persona humana de carácter inderogable, tal como están consagrados en la Convención Americana sobre Derechos Humanos, en la Declaración Americana de los Derechos y Deberes del Hombre y en la Declaración Universal de Derechos Humanos”.

En tercer lugar, una de las consecuencias de los crímenes internacionales es que, desde la perspectiva internacional procesal, genera una obligación inmediata en todos los Estados que componen la comunidad internacional de investigar, perseguir, sancionar a los que sean hallados responsables del crimen, y procurar una reparación integral para las víctimas. Este verdadero derecho-deber de persecución universal que le asiste a cualquier Estado de la comunidad internacional se ve complementado por otra regla procesal reflejada en el principio aut dedere aut iudicare: o lo juzgan o lo extraditan. Dicho de otro modo, encontrándose en el Estado de Chile un presunto responsable del crimen de desaparición forzada de personas, cualquiera que sea su nacionalidad y donde sea que haya cometido el crimen, el Estado se encuentra obligado a extraditarlo -entregarlo a otro Estado que sí quiera juzgarlo- o a juzgarlo.

Por otra parte, no hay que olvidar la estrecha vinculación que existe entre el principio de jurisdicción universal y el derecho humano inderogable al acceso a la justicia y el derecho a la reparación adecuada de las víctimas de violaciones a los derechos humanos y al Derecho Internacional Humanitario. De esta manera se encuentra consagrada la jurisdicción universal en el Principio 5 de los Principios y directrices básicos sobre el derecho de las víctimas de violaciones de las normas internacionales de derechos humanos y del derecho internacional humanitario a interponer recursos y obtener reparaciones. ${ }^{32}$ En la etapa de discusión de estas directrices, el Relator Theo Van

31 Corte I.D.H.: Caso Goiburú y otros vs. Paraguay. Fondo, Reparaciones y Costas. Sentencia de 22 de septiembre de 2006. Serie C No. 153, par. 84, p. 60.

32 "5. Con tal fin, cuando así lo disponga un tratado aplicable o lo exija otra obligación jurídica internacional, los Estados incorporarán o aplicarán de otro modo dentro de su derecho interno las disposiciones apropiadas relativas a la jurisdicción universal. Además, cuando así lo disponga un tratado aplicable o lo exija otra obligación jurídica internacional, los Estados deberán facilitar la extradición o entrega de los culpables a otros Estados y a los órganos judiciales internacionales competentes y prestar asistencia judicial y otras formas de cooperación para la administración de la justicia internacional, en particular 
Boven resaltó esta estrecha vinculación entre acceso a la justicia y ejercicio de la jurisdicción universal. ${ }^{33}$

El principio de jurisdicción universal establece la competencia de los tribunales penales del foro doméstico de un Estado para investigar, juzgar y sancionar a un presunto responsable de crímenes contra la humanidad. Una regla auxiliar que fortalece esta jurisdicción universal es el principio aut dedere aut iudicare, como un modo de asegurar el juzgamiento en todo lugar y bajo cualquier circunstancia del responsable de haber cometido un crimen contra la humanidad. Esta regla indica que encontrándose en el territorio de un Estado un presunto responsable de un crimen internacional, el Estado en cuestión tiene la obligación de juzgarlo o de extraditarlo, ya que, en virtud del principio de jurisdicción universal, habrá otro Estado que será igualmente competente para investigar, juzgar y sancionar al responsable. Este principio general y norma de derecho consuetudinario, se ha codificado en algunos instrumentos internacionales, tales como la Convención contra la Tortura y en la Convención Interamericana de Desaparición Forzada de Personas. De más está decir que la prohibición de la tortura o la prohibición de la desaparición forzada de personas son normas de ius cogens que generan obligaciones erga omnes, en consecuencia, el deber de todos los Estados de perseguir el incumplimiento de estas normas, tal como fue afirmado en la famosa sentencia de la Corte Internacional de Justicia, en el caso de la Barcelona Traction.

En este contexto, ¿cómo puede ser posible -como sostienen los parlamentarios en su requerimiento- que estas normas y principios sean contrarios a la Constitución? Aquí no se trata de delegar jurisdicción en un nuevo Tribunal, ni de crear un nuevo tribunal, ni de ceder soberanía o competencias soberanas. Se trata de que el Estado de Chile se encuentre obligado a juzgar a criminales internacionales. Esta obligación es una norma de ius cogens y produce efectos erga omnes, esto es, todos los Estados miembros de la comunidad internacional se encuentran igualmente obligados a esta persecución universal. Esta es la única manera de combatir con las armas del Derecho las barbaries y las atrocidades que repugna a la comunidad internacional. De otra manera, habría que volver a etapas más atrasadas de nuestra civilización y procurarse, individualmente, la autotutela violenta de sus derechos.

En cuarto lugar, en esta parte se hace fuertemente presente el rol educativo del Derecho en cuanto a orientar al individuo y a la sociedad a conductas que contribuyan

asistencia y protección a las víctimas y a los testigos, conforme a las normas jurídicas internacionales de derechos humanos y sin perjuicio de disposiciones jurídicas internacionales tales como las relativas a la prohibición de la tortura y otros tratos o penas crueles, inhumanos o degradantes". Principios y directrices básicos sobre el derecho de las víctimas de violaciones manifiestas de las normas internacionales de derechos humanos y de violaciones graves del derecho internacional humanitario a interponer recursos $y$ obtener reparaciones. Doc. Asamblea General, A/RES/60/147, de fecha 16 de diciembre de 2005.

33 Comisión de Derechos Humanos: Informe del Grupo de Trabajo del período de sesiones sobre la administración de la justicia y la cuestión de la indemnización. Doc. E/CN.4/Sub.2/1996/16, de fecha 13 de agosto de 1996, par. 28 
a alcanzar ciertos valores como la tolerancia, el pluralismo, la dignidad humana y la paz social. Por esta razón es que el Derecho Internacional, en cuanto a los crímenes internacionales, contiene un mensaje altamente ético de valoración de la dignidad humana, a saber, la comunidad internacional en su conjunto no tolera la barbarie ni las atrocidades que, finalmente, constituyen un vejamen para la humanidad. De este modo, el Derecho Internacional le indica al individuo que el responsable de violaciones a los derechos humanos constitutivas de crímenes contra la humanidad no tiene refugio seguro, ni en los hechos ni en el Derecho. En esta línea, el Tribunal Constitucional ha señalado claramente que frente a los crímenes atroces que ha presenciado la humanidad en el siglo XX no se acepta ni puede aceptarse la impunidad. ${ }^{34}$

El preámbulo de la Declaración sobre la protección de todas las personas contra las desapariciones forzadas, señala que "las desapariciones forzadas afectan los valores más profundos de toda sociedad respetuosa de la primacía del derecho, de los derechos humanos y de las libertades fundamentales". Del mismo modo, el preámbulo de la Convención Interamericana sobre Desaparición Forzada de Personas, afirma que "la desaparición forzada de personas viola múltiples derechos esenciales de la persona humana de carácter inderogable". Por su parte, el Preámbulo de la Convención Internacional para la protección de todas las personas contra las desapariciones forzadas reconoce "que la Carta de las Naciones Unidas impone a los Estados la obligación de promover el respeto universal y efectivo de los derechos humanos y libertades fundamentales". Finalmente, el Preámbulo del Estatuto de Roma señala que "que los crímenes más graves de trascendencia para la comunidad internacional en su conjunto no deben quedar sin castigo y que, a tal fin, hay que adoptar medidas en el plano nacional e intensificar la cooperación internacional para asegurar que sean efectivamente sometidos a la acción de la justicia" y que los Estados están "decididos a poner fin a la impunidad de los autores de esos crímenes y a contribuir así a la prevención de nuevos crímenes". Además, recuerda que "es deber de todo Estado ejercer su jurisdicción penal contra los responsables de crímenes internacionales”. El Preámbulo de los instrumentos internacionales es de fundamental importancia en la fijación del sentido y alcance de una norma internacional, de acuerdo con el artículo 31 de la Convención de Viena sobre Derecho de los Tratados. ${ }^{35}$

34 Tribunal Constitucional de Chile: Requerimiento respecto del Estatuto de Roma de la Corte Penal Internacional, adoptado en dicha ciudad el 17 de julio de 1998. Rol №346-2002. Sentencia de fecha 8 de abril de 2002. Considerando $92^{\circ}$.

35 "31. Regla general de interpretación. 1. Un tratado deberá interpretarse de buena fe conforme al sentido corriente que haya de atribuirse a los términos del tratado en el contexto de estos y teniendo en cuenta su objeto y fin. 2. Para los efectos de la interpretación de un tratado. el contexto comprenderá, además del texto, incluidos su preámbulo y anexos: a) todo acuerdo que se refiera al tratado y haya sido concertado entre todas las partes con motivo de la celebración del tratado: b) todo instrumento formulado por una o más partes con motivo de la celebración del tratado y aceptado por las demás como instrumento referente al tratado; 3. Juntamente con el contexto, habrá de tenerse en cuenta: a) todo acuerdo ulterior entre las partes acerca de la interpretación del tratado o de la aplicación de sus disposiciones: b) toda práctica ulteriormente seguida en la aplicación del tratado por la cual conste el 
Estos principios que elevan la vara ética en el comportamiento de la sociedad y en la utilización y administración del poder, son el trasfondo de la Convención Interamericana sobre Desaparición Forzada de Personas, que fue declarada inconstitucional por el Tribunal Constitucional, así como de gran cantidad de otros tratados de derechos humanos, tales como de la Convención Internacional para la protección de todas las personas contra las desapariciones forzadas y el Estatuto de Roma, por ejemplo.

Todos estos principios y valores, que poseen un alto componente ético-social, constituyen el sustratum de los derechos fundamentales, y por esa vía, se encuentran incorporados en los principios y valores que están incorporados en la Carta Fundamental. Estos principios y valores permiten introducir un principio de coherencia en la interpretación jurídica. La coherencia en la interpretación no significa que el intérprete haga, forzadamente, todos los esfuerzos posibles por hacer calzar las reglas. La coherencia es, por supuesto, lo contrario a este esfuerzo forzado, casi artificial -por no decir discrecional y antojadizo- por armonizar las reglas provenientes del derecho interno y del Derecho Internacional. Un ejemplo claro de esta situación forzada se encuentra presente en el caso Liquiñe, en donde queda de manifiesto, en la sentencia de la Corte Suprema, que se hacen todos los esfuerzos argumentativos para justificar la aplicación de la media prescripción o prescripción gradual, regulada en el derecho doméstico en el artículo 103 del Código Penal como circunstancia atenuante, mientras, al mismo tiempo, se declara el mismo hecho punible -a la sazón, equivalente a la desaparición forzada de personas- como imprescriptible, en virtud del Derecho Internacional consuetudinario e invocando como prueba la Convención sobre la imprescriptibilidad de los crímenes de guerra y de los crímenes de lesa humanidad de 26 de noviembre de $1968 .^{36}$

Esta es una incoherencia que nosotros podríamos denominar "el sí pero no" de la jurisdicción. Todo lo anterior, lo hace la Corte Suprema olvidando que se trata de una figura criminal regulada íntegramente por el Derecho Internacional penal, frente a la cual no cabe la aplicación del derecho penal doméstico, ni en sus reglas escritas ni en sus principios, que han sido previstas para hechos totalmente distintos a los de la causa, tanto en su naturaleza como en su envergadura. A propósito de la naturaleza y envergadura de la desaparición forzada de personas, Ciruzzi ha señalado, citando a la Comisión de Derechos Humanos de Guatemala, que "la desaparición forzada o involuntaria constituye una forma permanente de tortura psicológica para los familiares de la víctima y, de manera indirecta, sobre la sociedad en su conjunto a la cual se pretende aterrorizar". ${ }^{37}$ Esta naturaleza especialmente compleja, seria y grave de la desapa-

acuerdo de las partes acerca de la interpretación del tratado: c) toda forma pertinente de derecho internacional aplicable en las relaciones entre las partes. 4. Se dará a un término un sentido especial si consta que tal fue la intención de las partes". Convención de Viena sobre el derecho de los tratados. Adoptada en Viena, el 23 de mayo de 1969. U.N. Doc A/CONF.39/27 (1969), 1155 U.N.T.S. 331, entered into force January 27, 1980.

36 Corte Suprema: Secuestro calificado de campesinos en Liquiñe. Recurso de Casación. Rol 4662-2007. Sentencia de fecha 25 de septiembre de 2008.

${ }^{37}$ Ciruzzi, María Susana: El delito de desaparición forzada de personas. Fabián Di Plácido, Buenos Aires, 2005, p. 214. 
rición, que afecta a niños, queda en evidencia en las palabras del Relator Theo Van Boven, quien señaló en su estudio sobre las desapariciones de niños en Argentina, que "eliminar desde la raíz a cierto tipo de oposición existente en la sociedad argentina fue el objetivo que dio forma a la actividad represiva de naturaleza genocida, basada en las ideas políticas de las víctimas, o en las de sus familiares, o parientes cercanos. Las desapariciones de niños de muy corta edad y de niños nacidos durante el cautiverio de sus madres, se inscribe dentro de este contexto. Los hijos de subversivos no debían volver a sus familias porque habrían podido formarse dentro del mismo cuadro moral y político que había llevado a sus padres a la subversión". ${ }^{38}$

Frente a este tipo de hechos punibles, lo que cabe es la aplicación por el juez penal interno de todo el estatuto del Derecho Internacional previsto para este tipo de ilícitos. En este mismo sentido se ha pronunciado la Comisión Internacional de Juristas al señalar que "[c]omo delitos internacionales, la incriminación y el régimen de responsabilidad penal de las graves violaciones de derechos humanos constitutivas de crímenes internacionales, como lo son las desapariciones forzadas, son establecidas por el derecho internacional con independencia de la que pueda establecerse en el derecho interno de los Estados". 39

En este sentido, este estatuto internacional especial se encuentra muy bien resumido en el Mensaje del Presidente de la República de fecha 18 de abril de 1995 por el cual somete a la aprobación del Congreso la Convención Interamericana sobre Desaparición Forzada de Personas. ${ }^{40}$ En efecto, el Gobierno señala claramente que "la Convención tipifica, el delito de desaparición forzada de personas como un delito internacional. Esta calificación tiene aparejadas las siguientes consecuencias jurídicas: a) Responsabilidad individual y responsabilidad internacional del Estado; b) Inadmisibilidad de la eximente de obediencia debida a órdenes superiores; c) Jurisdicción universal; d) Obligación de extraditar o juzgar a los responsables del delito; e) Obligación de no otorgar asilo a los responsables del delito; f) Imprescriptibilidad de la acción; g) Improcedencia de beneficiarse de actos del Poder Ejecutivo o Legislativo de los cuales pueda resultar la impunidad de los hechos constitutivos de la desaparición forzada de personas; y h) Obligación de los Estados de investigar y sancionar a los responsables del delito".

38 Boven, Theo Van: Prevention of the disappearance of children: Report prepared by Theo van Boven pursuant to Sub-Commission decision 1987/107 and transmitted by the Chairman of its 39th session. Doc. E/CN.4/Sub.2/1988/19, 10 August 1988.

39 Comisión Internacional de Juristas: Amicus Curiae de la Comisión Internacional de Juristas ante la Sala Penal Transitoria de la Corte Suprema de Justicia de la República del Perú sobre la desaparición forzada de Ernesto Castillo Páez (Recurso de Nulidad: expediente 2779-2006), 28 de febrero de 2007, par. 11, p. 6.

40 Mensaje de S.E. el Presidente de la República con el que inicia un Proyecto de Acuerdo relativo a la Convención Interamericana sobre Desaparición Forzada de Personas. Mensaje $\mathrm{N}^{\circ}$ 616-330. Santiago, abril 18 de 1995; Convención Interamericana sobre Desaparición Forzada de Personas, suscrita en Belém do Pará, Brasil, el 9 de junio de 1994, en el Vigésimo Cuarto Período Ordinario de Sesiones de la Asamblea General de la Organización de los Estados Americanos. 


\section{$\mathrm{V}$ LAS OBLIGACIONES INTERNACIONALES DE CHILE}

Esta regulación de la Desaparición forzada de personas se encuentra muy bien fundada en el Derecho Internacional. Uno de los primeros antecedentes que se pueden citar es el Decreto alemán Nacht und Nebel, dictado por el Mariscal Keitel, por instrucciones de Hitler, destinado a la detención, desaparición y eliminación de los oponentes al régimen nazi, durante la Segunda Guerra Mundial. ${ }^{41}$

En el concierto regional, la Organización de Estados Americanos (en adelante, la OEA), a través de su Resolución 666 de 1983, declaró que "la práctica de la desaparición forzada de personas en América es una afrenta a la conciencia del Hemisferio y constituye un crimen de lesa humanidad". ${ }^{42}$ A partir de esa fecha, la Organización ha constantemente reiterado este principio. ${ }^{43}$

Por su parte, el 26 de septiembre de 1984, la Asamblea Parlamentaria del Consejo de Europa, aprobó la Resolución $\mathrm{N}^{\circ} 828$ relativa a la desaparición forzada de personas. En esta Resolución, la Asamblea señaló que "tales desapariciones son una flagrante violación a una amplia variedad de derechos humanos reconocidos en los instrumentos internacionales sobre protección de los derechos humanos (Declaración Universal de Derechos Humanos, Pacto Internacional de Derechos Civiles y Políticos, Convención Europea de Derechos Humanos), en particular el derecho a la vida, la libertad y seguridad de las personas, el derecho a no ser sometido a tortura, la libertad según la cual nadie puede ser detenido o arrestado arbitrariamente, y el derecho a un juicio justo y público". ${ }^{44}$ En este mismo sentido se había pronunciado en el año 1981, el Grupo de Trabajo

41 Decreto Nacht und Nebel (Noche y Niebla): Directiva para la persecución de las infracciones cometidas contra el Reich o las fuerzas de ocupación en los territorios ocupados o Richtlinien für die Verfolgung von traftaten gegen das Reich oder die Besatzungsmacht in den besetzten Gebieten. Orden de Hitler del 7 de diciembre de 1941 y que el mariscal Wilhelm Keitel, firmó y publicó el 12 de diciembre de 1941 .

42 OEA: Resolución AG/RES. 666 (XIII-0/83) de 18 de noviembre de 1983; Comisión Internacional de Juristas: Amicus Curiae de la Comisión Internacional de Juristas ante la Sala Penal Transitoria de la Corte Suprema de Justicia de la República del Perú sobre la desaparición forzada de Ernesto Castillo Páez (Recurso de Nulidad: expediente 2779-2006), 28 de febrero de 2007, par. 9.

43 Vid. Resoluciones AG/RES. 742 (XIV-0/84), adoptada el 17 de noviembre de 1984, par. 4; AG/RES. 950 (XVIII-0/88), de 19 de noviembre de 1988, par. 4; AG/RES. 1022 (XIX-0/89), de 10 de noviembre de 1989, párrafo 7; y AG/RES. 1044 (XX-0/90), de 8 de junio de 1990, par. 6.

44 "Considering that such disappearances are a flagrant violation of a whole range of human rights recognised in the international instruments on the protection of human rights (Universal Declaration of Human Rights, International Covenant on Civil and Political Rights, European Convention on Human Rights), in particular the right to life, liberty and security of persons, the right not to be subjected to torture, freedom from arbitrary arrest or detention, and the right to a fair and public trial". Parliamentary Assembly: Resolution 828 (1984) on enforced disappearances. Text adopted by the Assembly on 26 September 1984 (9th Sitting), par. 4; "La desaparición forzada de seres humanos constituye una violación múltiple y continuada de numerosos derechos reconocidos en la Convención y que los Estados Partes están obligados a respetar y garantizar”. Cfr. Corte I.D.H.: Caso Velásquez Rodríguez vs. Honduras. Fondo. Sentencia de 29 de julio de 1988. Serie C No. 4, par. 155, p. 32. 
sobre Desaparición Forzada de Personas cuando señaló que estas conductas violaban en mayor o menos medida todos los derechos humanos de esas personas. ${ }^{45}$

La Asamblea Parlamentaria reiteró los siguientes principios relativos a la desaparición forzada de personas: a) la desaparición forzada de personas es un crimen contra la humanidad, el cual no puede ser considerado un crimen político y por tanto está sujeto a la extradición, no está sujeto a limitaciones y no puede ser cubierto por leyes de amnistía; b) las personas responsables de desaparición forzada de personas pueden ser perseguidas no sólo en el país en el cual cometieron el crimen, sino en cualquier país en el cual hayan sido arrestados. ${ }^{46}$

Desde el punto de vista de los órganos internacionales de control de los derechos humanos, el Comité de Derechos Humanos (en adelante, el CDH) se ha pronunciado en diversas oportunidades sobre el crimen de desaparición forzada de personas, entre otras cosas, para afirmar la obligación de los Estados de regular en su derecho penal interno, conforme a los principios del Derecho Internacional, la figura de la desaparición forzada de personas. ${ }^{47}$

En el nivel internacional regional, la Comisión Interamericana de Derechos Humanos (en adelante, la CIDH) ha señalado desde 1983 que la desaparición forzada de personas es un crimen contra la humanidad. En efecto, a propósito de la situación de Argentina entre los años 1983-1984, la CIDH ha sostenido que "el Poder Judicial en pronunciamientos sobre causas bajo su conocimiento ha declarado la desaparición de personas como un "crimen permanente o continuado", manteniendo con este criterio la justicia ordinaria su competencia para conocer y definir las causas judiciales sobre

45 Working Group on Enforced Disappearances: Report of the Working Group on enforced or involuntary disappearances. Doc. E/CN.4/1435, 26 january 1981, par. 186.

46 "i. Enforced disappearance is a crime against humanity, which: 1. cannot be considered a political offence and is therefore subject to the extradition laws; 2 . is not subject to limitation; 3 . may not be covered by amnesty laws; ii. Persons responsible for enforced disappearance may be prosecuted not only in the country in which the offence was committed, but in any country in which they have been arrested". Parliamentary Assembly: Resolution 828 (1984) on enforced disappearances. Text adopted by the Assembly on 26 September 1984 (9th Sitting), par. 13; En el caso Nikolic, el Tribunal Penal para la ex Yugoslavia señaló los componentes de los crímenes contra la humanidad según el Estatuto del TPIY. En este caso, el Tribunal especificó: "First, the crimes must be directed at a civilian population, specifically identified as a group by the perpetrators of those acts. Secondly, the crimes must, to a certain extent, be organised and systematic. Although they need not be related to a policy established at State level, in the conventional sense of the term, they cannot be the work of isolated individuals alone. Lastly, the crimes, considered as a whole, must be of a certain scale and gravity". ICTY: Prosecutor v. Nikolic, Rule 61 Decision, Trial Chamber, 20 Oct. 1995, (hereafter Prosecutor v. Nikolic, Rule 61 Decision), par. 26; Cfr. ICTY: The Prosecutor v. Zoran Kupreskic, Mirjan Kupreskic, Vlatko Kupresckic, Drago Josipovic, Dragan Papic, Vladimir Santic, also known as "Vlado”. Case No. IT-95-16-T. Judgement of: 14 January 2000, par. 566.

47 Comité de Derechos Humanos: Observaciones finales del Comité de Derechos Humanos: Honduras. Documento de Naciones Unidas CCPR/C/HND/CO/1, 13 de diciembre de 2006, par. 5; Comité de Derechos Humanos: Caso Nydia Erika Bautista c. Colombia. Comunicación N 563/1993. Decisión de 13 noviembre de 1995. Documento de las Naciones Unidas CCPR/C/55/D/563/1993, par. 8.6. 
esta aberrante práctica, que ha sido declarada por la Asamblea General de la OEA como un crimen de lesa humanidad". ${ }^{48}$

Por su parte, la Corte Interamericana de Derechos Humanos (en adelante, la Corte IDH) ha señalado reiteradas veces que la desaparición forzada de personas constituye un crimen contra la humanidad. En efecto, ya desde sus primeras sentencias, en el famoso caso Velásquez Rodríguez, la Corte IDH ha señalado que "la doctrina y la práctica internacionales han calificado muchas veces las desapariciones como un delito contra la humanidad". ${ }^{49}$

El ámbito europeo no ha estado exento de este verdadero flagelo contra una multiplicidad de derechos humanos. En efecto, la Corte Europea de Derechos Humanos (en adelante, la Corte EDH) ha conocido de diversos casos de desaparición forzada de personas, proporcionándoles un tratamiento muy convergente con aquel que ha prodigado la Corte IDH. Por ejemplo, en el caso Kurt, la Corte EDH reconoció, al determinar el derecho internacional relevante para el caso, que la práctica sistemática de la desaparición forzada era un crimen contra la humanidad. ${ }^{50}$

Por su parte, el Tribunal Penal Internacional para la ex Yugoslavia, reconoció expresamente, en el caso kupreskic, la desaparición forzada de personas como un crimen contra la humanidad y que este ilícito penal equivaldría a un acto inhumano. ${ }^{51}$

48 CIDH: Informe Anual 1983-1984, Capítulo IV, par. 12 y Capítulo V, I.3, OEA/Ser.L/V/II.63 doc. 10 de 28 de septiembre de 1984; Cfr. Informe Anual de 1986-1987, Capítulo V.II, OEA/Ser.L/V/II.71 Doc. 9 rev. 1 de 22 de septiembre de 1987; Informe Anual de 1987-1988, Capítulo IV, OEA/Ser.L/V/II.74 Doc. 10 rev. 1 de 16 de septiembre de 1988; Informe Anual 1990-1991, Capítulo V, OEA/Ser.L/V/II.79, Doc. 12 Rev. 1 de 22 de febrero de 1991; e Informe Anual de 1991, Capítulo IV, OEA/Ser.L/V/II.81 Doc. 6 Rev. 1 de 14 de febrero de 1992.

49 Corte I.D.H.: Caso Velásquez Rodríguez vs. Honduras. Fondo. Sentencia de 29 de julio de 1988. Serie C No. 4, par. 153, p. 31; Corte I.D.H.: Caso Godínez Cruz vs. Honduras, Sentencia de 20 de enero de 1989, Serie C N ${ }^{\circ}$ 5, par. 163 a 167; Corte I.D.H.: Caso 19 Comerciantes vs. Colombia, Sentencia de 5 de julio de 2004, Serie C N ${ }^{\circ}$ 109, par. 142; Corte I.D.H.: Caso Hermanas Serrano Cruz vs. El Salvador. Excepciones preliminares, Sentencia de 23 de noviembre de 2004, Serie C N ${ }^{\circ} 118$, par. 100 a 106; Corte I.D.H.: Caso Gómez Palomino vs. Perú, Sentencia de 22 de noviembre de 2005, Serie C N ${ }^{\circ} 136$, par. 92; Corte I.D.H.: Caso Goiburú y otros vs. Paraguay, Sentencia de 22 de septiembre de 2006, Serie $\mathrm{C} \mathrm{N}^{\circ} 153$, par. 82.

50 E.C.H.R.: Case of Kurt v. Turkey (15/1997/799/1002). Judgment, 25 May 1998, par. 64; Cfr. E.C.H.R.: Kaya c. Turquía, demanda $N^{\circ} 22535 / 93$, sentencia del 28 de marzo de 2000; E.C.H.R.: Tas c. Turquía, demanda $N^{\circ} 24396 / 94$, sentencia del 14 de noviembre de 2000; E.C.H.R.: Cicek c. Turquía, demanda $\mathrm{N}^{\circ} 25704 / 94$, sentencia del 27 de febrero de 2001.

51 "Less broad parameters for the interpretation of "other inhumane acts" can instead be identified in international standards on human rights such as those laid down in the Universal Declaration on Human Rights of 1948 and the two United Nations Covenants on Human Rights of 1966. Drawing upon the various provisions of these texts, it is possible to identify a set of basic rights appertaining to human beings, the infringement of which may amount, depending on the accompanying circumstances, to a crime against humanity. Thus, for example, serious forms of cruel or degrading treatment of persons belonging to a particular ethnic, religious, political or racial group, or serious widespread or systematic manifestations of cruel or humiliating or degrading treatment with a discriminatory or persecutory intent no doubt amount to crimes against humanity: inhuman or degrading treatment is prohibited by the 
Desde un punto de vista más específico, podemos encontrar tribunales que también se han pronunciado sobre la desaparición forzada de personas, tales como la Cámara de Derechos Humanos de Bosnia-Herzegovina, quien ha aludido a la desaparición forzada de personas como un crimen internacional, en los casos Palic y Unkovic. ${ }^{52}$

¿Por qué es importante toda esta jurisprudencia y pronunciamientos de tribunales y órganos de control? Porque, tal como ha señalado Naqvi, "[a]unque, según el artículo 38 1) d) del Estatuto de la Corte Internacional de Justicia (CIJ), las decisiones judiciales sólo se consideran "un medio auxiliar para la determinación de las reglas de derecho", "desempeñan un papel de creciente importancia en el reconocimiento de diferentes derechos humanos como derechos consuetudinarios", y el peso acumulativo de esta jurisprudencia, sumado a la de los órganos y tribunales de derechos humanos, 'influye en el desarrollo y la consolidación del derecho consuetudinario de los derechos humanos'". ${ }^{3}$

Por otra parte, la Corte I.D.H. ha reforzado este principio de la desaparición forzada como crimen internacional, a través de las obligaciones positivas que emanan de la Convención Americana de Derechos Humanos y, en general, del Derecho Internacional de los derechos humanos. En efecto, la Corte ha afirmado férreamente la obligación del Estado de organizar el aparato estatal de manera de asegurar y garantizar a

United Nations Covenant on Civil and Political Rights (Article 7), the European Convention on Human Rights, of 1950 (Article 3), the Inter-American Convention on Human Rights of 9 June 1994 (Article 5) and the 1984 Convention against Torture (Article 1). Similarly, the expression at issue undoubtedly embraces the forcible transfer of groups of civilians (which is to some extent covered by Article 49 of the IVth Convention of 1949 and Article 17(1) of the Additional Protocol II of 1977), enforced prostitution (indisputably a serious attack on human dignity pursuant to most international instruments on human rights), as well as the enforced disappearance of persons (prohibited by General Assembly Resolution 47/133 of 18 December 1992 and the Inter-American Convention of 9 June 1994). Plainly, all these, and other similar acts, must be carried out in a systematic manner and on a large scale. In other words, they must be as serious as the other classes of crimes provided for in the other provisions of Article 5". ICTY: The Prosecutor v. Zoran Kupreskic, Mirjan Kupreskic, Vlatko Kupresckic, Drago Josipovic, Dragan Papic, Vladimir Santic, also known as "Vlado". Case No. IT-95-16-T. Judgement of: 14 January 2000, par. 566.

52 Decision on Admissibility and Merits of 11 January 2001, Palic v. Republika Srpska, Caso $\mathrm{n}^{\circ} \mathrm{CH} / 99 /$ 3196; Decision on Admissibility and Merits of 9 November 2001, Unkovic v. Federation of Bosnia and Herzegovina, Caso ${ }^{\circ} \mathrm{CH} / 99 / 2150$; Decision on Admissibility and Merits of 7 March 2003, "Srebrenica Cases", caso $n^{\circ} \mathrm{CH} / 01 / 8365$ y otros, par. 220 (4); "La Cámara de Derechos Humanos para Bosnia y Herzegovina es un tribunal de derechos humanos establecido con arreglo al anexo 6 del Acuerdo de Paz de Dayton de 14 de diciembre de 1995 con el mandato de dictaminar de modo definitivo y vinculante sobre las violaciones presuntas o manifiestas del Convenio Europeo de Derechos Humanos y sobre la discriminación presunta o manifiesta en el disfrute de cualquiera de los derechos enumerados en 15 tratados internacionales y europeos de derechos humanos". Comisión de Derechos Humanos: Informe presentado por el Sr. Manfred Nowak, experto independiente encargado de examinar el marco internacional existente en materia penal y de derechos humanos para la protección de las personas contra las desapariciones forzadas o involuntarias, de conformidad con el párrafo 11 de la resolución 2001/46 de la Comisión. Doc. E/CN.4/2002/71, de fecha 8 de enero de 2002, par. 39, p. 23.

53 NAQvi, Yasmin: "El derecho a la verdad en el derecho internacional: ¿realidad o ficción?", en Revista Internacional de la Cruz Roja, núm. 862 (2006), pp. 161-193, especialmente, p. 184. 
los individuos los derechos reconocidos en la Convención. En este sentido, en el caso Velásquez Rodríguez, la Corte señaló que "[l]a obligación de garantizar el libre y pleno ejercicio de los derechos humanos no se agota con la existencia de un orden normativo dirigido a hacer posible el cumplimiento de esta obligación, sino que comparta la necesidad de una conducta gubernamental que asegure la existencia, en la realidad, de una eficaz garantía del libre y pleno ejercicio de los derechos humanos" ${ }^{54}$ La expresión "en la realidad" hace referencia a un deber del Estado de garantía efectiva y cierta de los derechos humanos, no teórica o ilusoria. Este principio se encuentra en perfecta consonancia con lo señalado por la Corte Europea de Derechos Humanos, por ejemplo, en el caso Airey. Así, en este caso la Corte ha señalado que si la Convención Europea de Derechos Humanos "enuncia por lo esencial derechos civiles y políticos, muchos de ellos tienen prolongaciones de orden económico y social" ya que "ningún límite definitivo separa la esfera de los derechos económicos y sociales del terreno de la Convención: se trata de proteger derechos no teóricos o ilusorios, sino concretos y efectivos". ${ }^{5}$

Además, en virtud de lo dispuesto en los artículos 1.1 y 2 de la Convención Americana de Derechos Humanos, "[e]l Estado está en el deber jurídico de prevenir, razonablemente, las violaciones de los derechos humanos, de investigar seriamente con los medios a su alcance las violaciones que se hayan cometido dentro del ámbito de su jurisdicción a fin de identificar a los responsables, de imponerles las sanciones pertinentes y de asegurar a la víctima una adecuada reparación". ${ }^{66}$ En este sentido, la Corte I.D.H. ha reconocido expresamente que dentro de las obligaciones que emanan para el Estado como consecuencia de la comisión de un crimen contra la humanidad como el de marras, se encuentra el deber de proporcionan a la víctima una reparación adecuada e integral. Esto último se ve complementado con lo señalado por el Comité de Derechos Humanos cuando ha señalado que "el Comité estima que el Estado Parte tiene el deber de investigar a fondo las presuntas violaciones de derechos humanos, en particular las desapariciones forzadas de personas y las violaciones del derecho a la vida, y de encausar penalmente, juzgar y castigar a quienes sean considerados responsables de esas violaciones. Este deber es aplicable a fortiori en los casos en que los autores de esas violaciones han sido identificados". ${ }^{57}$ Del mismo modo, el CDH ha reforzado el principio de que, derivado de la desaparición forzada de personas, la

54 Corte I.D.H.: Caso Velásquez Rodríguez vs. Honduras. Fondo. Sentencia de 29 de julio de 1988 . Serie C No. 4, par. 167 , p. 35.

55 "The Convention is intended to guarantee not rights that are theoretical or illusory but rights that are practical and effective. This is particularly so of the right of access to the courts in view of the prominent place held in a democratic society by the right to a fair trial”. E.C.H.R.: Case of Airey v. Ireland (Application no. 6289/73). Judgment, 9 October 1979, pars. 24 y 26.

56 Corte I.D.H.: Caso Velásquez Rodríguez vs. Honduras. Fondo. Sentencia de 29 de julio de 1988. Serie C No. 4, par. 174 , p. 36.

57 Comité de Derechos Humanos: Caso José Vicente y Amado Villafañe Chaparro, Luis Napoleón Torres Crespo, Ángel María Torres Arroyo y Antonio Hugues Chaparro Torres c. Colombia. Comunicación $\mathrm{N}^{\circ}$ 612/1995, Decisión de 29 de julio de 1997. Documento de las Naciones Unidas CCPR/C/60/D/ 612/1995, par. 8.8 . 
víctima y sus familiares tienen derecho a recibir una indemnización justa y adecuada. ${ }^{58}$ Igualmente, este Comité ha reforzado el derecho a la verdad en casos de crímenes internacionales, particularmente, de crímenes de desaparición forzada de personas, el cual se puede realizar por el Estado, inter alia, a través de una investigación criminal adecuada. El incumplimiento de este deber del Estado puede generar, a su vez, nuevas infracciones a los derechos humanos. ${ }^{59}$

Junto con estas obligaciones, de la Convención Americana de Derechos Humanos y del Derecho Internacional de los derechos humanos emanan restricciones al poder, que se traducen en limitaciones para el Estado. En efecto, claramente la Corte I.D.H. ha afirmado que "[e]stá más allá de toda duda que el Estado tiene el derecho y el deber de garantizar su propia seguridad. Tampoco puede discutirse que toda sociedad padece por las infracciones a su orden jurídico. Pero, por graves que puedan ser ciertas acciones y por culpables que puedan ser los reos de determinados delitos, no cabe admitir que el poder pueda ejercerse sin límite alguno o que el Estado pueda valerse de cualquier procedimiento para alcanzar sus objetivos, sin sujeción al derecho o a la moral. Ninguna actividad del Estado puede fundarse sobre el desprecio a la dignidad humana". ${ }^{0}$

Por esta razón, dada la envergadura de los bienes jurídicos protegidos, la atrocidad de la conducta, y la multiplicidad de las violaciones a los derechos humanos que comporta la desaparición forzada de personas, es que el Derecho Internacional de los derechos humanos y el Derecho Internacional penal han reconocido el principio de prohibición de la impunidad. La impunidad es un grave situación antijurídica que pone en peligro la existencia misma de la sociedad e implica una suerte de incumplimiento del Estado de su obligación de proporcionar garantías de no repetición. Una de las formas de combatir jurídicamente la impunidad y asegurar que se perseguirá, sancionará y reparará el mal causado, es a través del ejercicio de la jurisdicción universal. Esto último implica que todos los Estados tienen la obligación -deber del Estado de adecuar su derecho interno al Derecho Internacional- de tipificar la desaparición for-

58 "El Estado Parte debería modificar el Código Penal de forma que se tipifique el delito de desaparición forzada. Debe asimismo asegurar que los casos de desapariciones forzadas sean debidamente investigados, que los responsables sean juzgados y, en su caso, sancionados y que las víctimas o sus familiares reciban una indemnización justa y adecuada". Comité de Derechos Humanos: Observaciones finales del Comité de Derechos Humanos: Honduras. Documento de Naciones Unidas CCPR/C/HND/CO/1, 13 de diciembre de 2006, par. 5.

59 "Recuerda al Estado Parte que los familiares de las personas desaparecidas tienen derecho a recibir información sobre la suerte corrida por sus familiares y que no investigar las causas y circunstancias de la muerte de personas desaparecidas, y no informar sobre los lugares en que fueron enterradas aumenta la incertidumbre y por tanto el sufrimiento infligido a los familiares y puede equivaler a violación del artículo 7 del Pacto (párrafo 3 del artículo 2 y artículos 6 y 7)”. Comité de Derechos Humanos: Observaciones finales del Comité de Derechos Humanos: Bosnia y Herzegovina. Documento de Naciones Unidas CCPR/C/BIH/CO/1, de fecha 8 de diciembre de 2006, par. 14.

60 Corte I.D.H.: Caso Velásquez Rodríguez vs. Honduras. Fondo. Sentencia de 29 de julio de 1988. Serie C No. 4 , par. 154 , p. 32. 
zada como delito en la legislación penal y de "ejercer su jurisdicción frente a todo presunto autor de una desaparición forzada que se encuentre en su territorio, independientemente de su nacionalidad, la de la víctima o del lugar de comisión del delito". ${ }^{61}$ Además, esta obligación responde al compromiso de cooperación internacional del Estado que se encuentra consagrado, inter alia, en la Carta de la Organización de las Naciones Unidas y en la Carta de la Organización de Estados Americanos. Por supuesto, con mucha mayor razón tiene el deber de ejercer su jurisdicción si el presunto autor de una desaparición forzada es un nacional del Estado.

Todos estos principios relativos a la desaparición forzada de personas como crimen contra la humanidad se encuentran formando parte, como se ha visto, del derecho consuetudinario, y también, se han codificado, pasando a estar contenidos en una segunda fuente, a la sazón, convencional.

La Convención Interamericana sobre Desaparición Forzada de Personas fue aprobada por el Congreso de la República en el mes de julio de 2003. Sin embargo, se presentó un requerimiento de inconstitucionalidad por diversos senadores, según lo que disponía la Constitución antes de la Reforma de 2005 en su artículo $82 \mathrm{~N}^{\circ} 2$, el cual fue acogido por el Tribunal, pero invocando una inconstitucionalidad de forma, y declaró la inconstitucionalidad del acuerdo aprobatorio del Congreso. En consecuencia, desde la perspectiva del derecho internacional convencional, el crimen de desaparición forzada sigue sin ser incorporado al derecho interno, sin perjuicio de su vigencia en cuanto Derecho Internacional consuetudinario, tal y como diversos fallos de la Corte Suprema lo han reconocido expresamente. En efecto, en el caso Troncoso Muñoz, por ejemplo, la Corte Suprema afirmó el principio general de la supremacía del Derecho Internacional por sobre el derecho interno en el orden interno chileno y recalcó dicha "[p]rimacía de las normas internacionales de Derecho Internacional General que determina que, en los delitos de lesa humanidad, dichas disposiciones actualmente recepcionadas constitucionalmente vía tratado internacional y vinculantes desde antes como Principio General del Derecho Internacional de los Derechos Humanos, son obligatorias". ${ }^{62}$

La no incorporación del Derecho Internacional convencional sobre la desaparición forzada de personas ha repercutido, entre otras cosas, en la no regulación en el derecho positivo interno chileno del crimen internacional de desaparición forzada de personas. Esta es una de las razones que explican por qué los tribunales de justicia deben recurrir a una figura alternativa regulada en el derecho chileno, que mejor calce a la situación de desaparición forzada de personas, a saber, la contemplada en el artículo 141 del Código Penal, es decir, lo que se ha denominado secuestro permanente. Y

61 Comisión Internacional de Juristas: Amicus Curiae de la Comisión Internacional de Juristas ante la Sala Penal Transitoria de la Corte Suprema de Justicia de la República del Perú sobre la desaparición forzada de Ernesto Castillo Páez (Recurso de Nulidad: expediente 2779-2006) 28 de febrero de 2007, par. 9, p. 5.

62 Corte Suprema: Caso sobre el secuestro calificado de Troncoso Muñoz, Ricardo Aurelio y otros. Rol $\mathrm{N}^{\circ}$ 3452-2006. Sentencia de fecha 10 de mayo de 2007. Considerando $63^{\circ}$. 
esto, a su vez, explica por qué los tribunales nacionales, conociendo del crimen de desaparición forzada de personas, discurren y argumentan sobre la base de criterios propiamente de derecho penal interno, tales como la prescripción de la acción penal y, últimamente, la media prescripción. Estos criterios, desde la perspectiva de un sistema integral de derechos humanos y de la unidad del orden jurídico de los derechos humanos, divergen sustancialmente del derecho internacional penal y del derecho internacional de los derechos humanos. Cabe aquí tener presente que el crimen de desaparición forzada de personas - un crimen contra la humanidad- entra netamente dentro del ámbito del respeto y protección de los derechos humanos.

Tampoco se ha podido avanzar con la aprobación de la Convención Internacional para la protección de todas las personas contra las desapariciones forzadas ya que no se han reunido los quorum exigidos para ser aprobada y que requieren necesariamente los votos tanto del sector oficialista como de la oposición.

Tanto la Convención Interamericana sobre Desaparición Forzada de Personas como la Convención Internacional para la protección de todas las personas contra las desapariciones forzadas, se encuentra firmadas por el Estado de Chile lo cual genera o crea un principio de compromiso internacional de Chile y directamente, obligaciones jurídicas de conformidad con el Derecho Internacional, según lo previsto expresamente por la Convención de Viena sobre Derechos de los Tratados, y por el Derecho Internacional consuetudinario, en conjunto con la aplicación del principio básico de la buena fe que vincula al Estado de Chile. ${ }^{63}$ No huelga destacar que resulta de la mayor importancia jurídica relevar que la pertenencia de Chile a la Organización de Naciones Unidas y a la Organización de Estados Americanos, entre otras organizaciones internacionales intergubernamentales, implica la generación directa de obligaciones para el Estado de Chile, como miembro de la comunidad internacional. ${ }^{64}$

Esta falta de ratificación de la Convención Interamericana sobre Desaparición Forzada de Personas, no es sino una pequeña muestra de la falta de cumplimiento por parte de Chile de sus compromisos internacionales, revelando que sus declaraciones internas y externas en relación con los derechos humanos, son meras declamaciones

63 "26. "Pacta sunt servanda». Todo tratado en vigor obliga a las partes y debe ser cumplido por ellas de buena fe". Convención de Viena sobre el derecho de los tratados. Adoptada en Viena, el 23 de mayo de 1969. U.N. Doc A/CONF.39/27 (1969), 1155 U.N.T.S. 331, entered into force January 27, 1980; Además, existen las obligaciones que emanan de la firma de un tratado. "18. Obligación de no frustrar el objeto y el fin de un tratado antes de su entrada en vigor. Un Estado deberá abstenerse de actos en virtud de los cuales se frustren el objeto y el fin de un tratado: a) si ha firmado el tratado o ha canjeado instrumentos que constituyen el tratado a reserva de ratificación, aceptación o aprobación, mientras no haya manifestado su intención de no llegar a ser parte en el tratado". Convención de Viena sobre el derecho de los tratados. Adoptada en Viena, el 23 de mayo de 1969. U.N. Doc A/CONF.39/27 (1969), 1155 U.N.T.S. 331, entered into force January 27, 1980.

64 Por ejemplo, la obligación impuesta por la Carta, a los Estados miembros de la Organización de las Naciones Unidas, en particular por el Artículo 55, de promover el respeto universal y efectivo de los derechos humanos y de las libertades fundamentales. 
o simplemente decorativas. Por supuesto que en esta grave falta del Estado Chileno que compromete su credibilidad y su imagen de seriedad y de real compromiso con la democracia y el estado de derecho, están involucrados y son responsables, de una u otra manera, todos los sectores políticos y sociales. Los actores políticos por no concurrir con sus votos y los actores sociales por no asumir como una tarea primordial la presión de los actores políticos y la difusión de esta actuación en forma masiva entre la población para generar una opinión pública conciente, libre e informada, capaz de adoptar decisiones fundadas. Por ejemplo, resulta de la máxima importancia destacar la falta de cumplimiento de los compromisos internacionales, algunos de ellos tan básicos y elementales para el bienestar del individuo, las comunidades y pueblos, como, inter alia, el Protocolo Adicional a la Convención Americana sobre Derechos Humanos en materia de Derechos Económicos, Sociales y Culturales, "Protocolo de San Salvador"; el Protocolo Facultativo de la Convención sobre la eliminación de todas las formas de discriminación contra la mujer; la Convención Internacional para la protección de todas las personas contra las desapariciones forzadas; y, por supuesto, la falta de ratificación del Estatuto de Roma de la Corte Penal Internacional, de 1998. Además, en su momento, una vez que sea adoptado por la Asamblea General de las Naciones Unidas, será necesario ratificar el Protocolo Facultativo del Pacto Internacional de Derechos Económicos, Sociales y Culturales, cuya resolución ante el Consejo de Derechos Humanos fue patrocinada por el Gobierno de Chile. ${ }^{65}$

65 Vid. Protocolo Adicional a la Convención Americana sobre Derechos Humanos en materia de Derechos Económicos, Sociales y Culturales, "Protocolo de San Salvador", adoptado en San Salvador, el 17 de noviembre de 1988 y suscrito por Chile el 5 de junio de 2001; el Protocolo Facultativo de la Convención sobre la eliminación de todas las formas de discriminación contra la mujer, adoptada por la Asamblea General Asamblea General de las Naciones Unidas en su resolución A/54/4 de 6 de octubre de 1999 y suscrita por el Estado de Chile el 10 de diciembre de 1999; la Convención Internacional para la protección de todas las personas contra las desapariciones forzadas, adoptada por la Asamblea General de las Naciones Unidas en su Resolución 61/177 de fecha 20 de diciembre de 2006 y suscrita por Chile el 6 de febrero de 2007; y, el Estatuto de Roma de la Corte Penal Internacional, adoptado en dicha ciudad el 17 de julio de 1998, contenido en el Acta Final de la Conferencia Diplomática de Plenipotenciarios de las Naciones Unidas sobre el Establecimiento de una Corte Penal Internacional, y el Acta de Rectificación del Estatuto Original de la Corte Penal Internacional, de fecha 10 de noviembre de 1998; el Protocolo Facultativo del Pacto Internacional de Derechos Económicos, Sociales y Culturales. El Protocolo Facultativo del Pacto Internacional de Derechos Económicos, Sociales y Culturales, aprobado por unanimidad por el Consejo de Derechos Humanos el 18 de junio de 2008. El Protocolo habilita la presentación de peticiones individuales o colectivas ante el Comité de Derechos Económicos, Sociales y Culturales (órgano de vigilancia del PIDESC) por violaciones a los derechos fundamentales consagrados en el Pacto Internacional de Derechos Económicos Sociales y Culturales. Cfr. Doc. N.U. A/HRC/8/ L.2/Rev.1/Corr.1, de fecha 16 de junio de 2008; Asimismo, el Protocolo Facultativo de la Convención sobre los Derechos del Niño Relativo a la Participación de Niños en los Conflictos Armados, adoptado por la Asamblea General de las Naciones Unidas en su Resolución A/54/RES/263, de 16 de mayo de 2000, con su corrección al numeral 1. del Artículo 3, notificada por el Depositario con fecha 16 de agosto del mismo año, y suscrito por la República de Chile el 15 de noviembre de 2001 ; la Convención Internacional para la protección de todas las personas contra las desapariciones forzadas, adoptada por la Asamblea General de las Naciones Unidas en su Resolución 61/177 de fecha 20 de diciembre de 2006 y suscrita por Chile el 6 de febrero de 2007. 
Es cierto, se han dado pasos muy importantes, especialmente en el año 2008, tales como la ratificación de la Convención sobre los Derechos de los Pueblos Indígenas, del Segundo Protocolo Facultativo del Pacto Internacional de Derechos Civiles y Políticos Destinado a Abolir la Pena de Muerte, del Protocolo a la Convención Americana sobre Derechos Humanos Relativo a la Abolición de la Pena de Muerte, del Protocolo Facultativo de la Convención contra la Tortura y Otros Tratos o Penas Crueles, Inhumanos o Degradantes, y de la Convención sobre los Derechos de las Personas con Discapacidad y su Protocolo Facultativo. ${ }^{66}$

A estos importantes adelantos en materia de Derecho Internacional de los derechos humanos, deben sumarse instrumentos, de justiciabilidad y para la protección jurisdiccional de los individuos, aprobados con anterioridad, tales como la Convención sobre la Protección y Promoción de la Diversidad de las Expresiones Culturales y su Anexo; la Convención internacional sobre la protección de los derechos de todos los trabajadores migratorios y de sus familiares; el Protocolo para Prevenir, Reprimir y Sancionar la Trata de Personas, especialmente Mujeres y Niños, que complementa la Convención de las Naciones Unidas contra la Delincuencia Organizada Transnacional; el Protocolo Facultativo de la Convención sobre los Derechos del Niño relativo a la venta de niños, la prostitución infantil y la utilización de niños en la pornografía; el Convenio $\mathrm{N}^{\circ} 151$, sobre La protección del derecho de sindicación y los procedimientos para determinar las condiciones de empleo en la administración pública; la Convención Interamericana para Prevenir, Sancionar y Erradicar la Violencia contra la Mujer. ${ }^{67}$

60 Vid. En 2008 la aprobación del Segundo Protocolo Facultativo del Pacto Internacional de Derechos Civiles y Políticos Destinado a Abolir la Pena de Muerte, adoptado por la Asamblea General de las Naciones Unidas en su Resolución 44/128, de 15 de diciembre de 1989, y suscrito por la República de Chile el 15 de diciembre de 2001. Del mismo modo, se ha aprobado en 2008 el Protocolo a la Convención Americana sobre Derechos Humanos Relativo a la Abolición de la Pena de Muerte, adoptado en Asunción el 8 de junio de 1990, en el Vigésimo Período Ordinario de Sesiones de la Asamblea General de la Organización de los Estados Americanos, y suscrito por la República de Chile el 10 de septiembre de 2001. Junto con esto, se ha aprobado en 2008, el Protocolo Facultativo de la Convención contra la Tortura y Otros Tratos o Penas Crueles, Inhumanos o Degradantes, adoptada y abierta a la firma, ratificación y adhesión por la Asamblea General en su Resolución 77/199, de 18 de diciembre de 2002. Además, se aprobó también en 2008, la Convención sobre los Derechos de las Personas con Discapacidad y su Protocolo Facultativo, adoptados el 13 de diciembre de 2006 por la Asamblea General de la Organización de las Naciones Unidas, durante su $61^{\circ}$ Periodo Ordinario de Sesiones, celebrada en Nueva York y se publicó el D. S. № 201 en el Diario Oficial de fecha 17 de septiembre de 2008.

67 Vid. La Convención sobre la Protección y Promoción de la Diversidad de las Expresiones Culturales y su Anexo, adoptada el 20 de octubre de 2005, por la Conferencia General de la Organización de las Naciones Unidas para la Educación, la Ciencia y la Cultura, UNESCO, en su $33^{a}$ reunión, celebrada en París del 3 al 21 de octubre de 2005, y publicado el D. S. N ${ }^{\circ} 82$, en el Diario Oficial de fecha 27 de junio de 2007, como asimismo es extremadamente relevante para nuestro país la Convención internacional sobre la protección de los derechos de todos los trabajadores migratorios y de sus familiares, adoptada por la Asamblea General de la Organización de las Naciones Unidas en su resolución 45/158, de 18 de diciembre de 1990, suscrita por el Gobierno de la República de Chile el 24 de septiembre de 1993, aprobada por el Congreso con fecha 8 de enero de 2004 y publicado el D. S. $N^{\circ} 84$, en el D. O. de fecha 8 de junio de 2005. Además, se pueden mencionar el Protocolo para Prevenir, Reprimir y Sancionar la Trata de Personas, especialmente Mujeres y Niños, que complementa la Convención de las Naciones 
Sin embargo, todavía existen muchas normas sobre derechos humanos que tienden a proteger los derechos de importantes grupos vulnerables, influenciando y generando las bases para políticas públicas inclusivas, y normas que tienden a proteger al individuo y a la comunidad toda de la realización y repetición de conductas bárbaras y aberrantes, que no han sido ratificadas por Chile, respecto de las cuales, por tanto, al menos desde un punto de vista del derecho internacional convencional, nuestra sociedad se mantiene aislada.

\section{$\mathrm{VI}$ \\ VALORACIÓN FINAL}

1. La sentencia sobre la CIDFP se pronunció sobre las normas formales constitucionales que deben observarse por el Congreso para aprobar un tratado internacional. En este orden de cosas, esta sentencia reitera principios que ya habían sido enunciados en la sentencia que se pronunció sobre la constitucionalidad de la Convención de la OIT sobre derechos de los pueblos indígenas y tribales.

2. Estas dos sentencias influenciaron las modificaciones introducidas a la Constitución Política de la República bajo la reforma del año 2005. En consecuencia, estos pronunciamientos jurisdiccionales son relevantes porque han permitido avanzar el Derecho Constitucional positivo en cuanto a la incorporación del Derecho Internacional convencional al derecho interno.

Unidas contra la Delincuencia Organizada Transnacional, adoptado por la Asamblea General de las Naciones Unidas en su resolución A/RES/55/25, de 15 de noviembre de 2000, y suscrito por la República de Chile el 8 de agosto de 2002, aprobado por el Congreso con fecha 19 de agosto de 2004 y publicado el D. S. $\mathrm{N}^{\circ} 342$ en el D. O. con fecha 16 de febrero de 2005; el Protocolo Facultativo de la Convención sobre los Derechos del Niño relativo a la venta de niños, la prostitución infantil y la utilización de niños en la pornografía, adoptada por la Asamblea General de la Organización de las Naciones Unidas, en su Resolución A/RES/54/263 del 25 de mayo de 2000, suscrito por la República de Chile el 28 de junio de dicho año, con su corrección a la letra b) del Artículo 7, notificada por el depositario con fecha de 16 de agosto de 2000, aprobado por el Congreso con fecha 6 de noviembre de 2002, y publicado el D. S. $\mathrm{N}^{\circ} 225$ en el D. O. de fecha 6 de septiembre de 2003; El Convenio $\mathrm{N}^{\circ} 151$, sobre La protección del derecho de sindicación y los procedimientos para determinar las condiciones de empleo en la administración pública, adoptado por la Conferencia General de la Organización Internacional del Trabajo, congregada en Ginebra, el 7 de junio de 1978, aprobado por el Congreso Nacional con fecha 18 de abril de 2000 y publicado el D.S. N 1.539 en el D. O. con fecha 26 de diciembre de 2000; La Convención Interamericana para Prevenir, Sancionar y Erradicar la Violencia contra la Mujer, también denominada Convención de Belém do Pará, adoptada en Belém do Pará, Brasil, el 9 de junio de 1994, en el Vigésimo Cuarto Período Ordinario de Sesiones de la Asamblea General de la Organización de Estados Americanos, suscrita por Chile el 17 de octubre de 1994, aprobada por el Congreso con fecha 8 de septiembre de 1998 y publicado el D.S. N ${ }^{\circ} 1.640$ en el D.O. con fecha 11 de noviembre de 1998. 
3. En este sentido, dos aspectos son relevantes: primero, en cuanto a la naturaleza de los tratados internacional, que antes se asimilaban a la ley interna y ahora queda claro que los tratados internacionales, en el orden interno chileno, siguen siendo tratados internacionales: segundo, en cuanto al valor o rango jerárquico de los tratados internacionales, que antes por la asimilación de los tratados a la leyes, se decía que los tratados tenían el valor jerárquico de ley, en circunstancias que ahora queda claro que los tratados tienen un rango superior a la ley, por cuanto la propia Constitución señala que no pueden ser modificados ni dejados sin efecto sino es por las reglas del propio tratado o por las normas del Derecho Internacional general.

4. La sentencia del Tribunal Constitucional sobre la CIDFP no se pronunció sobre el fondo del requerimiento. Probablemente, la Convención Interamericana sobre Desaparición Forzada de Personas llegará nuevamente al Tribunal Constitucional y, en ese evento, ahora bajo la vigencia de la Reforma Constitucional del año 2005, el Tribunal deberá pronunciarse ponderando correctamente las disposiciones constitucionales con las obligaciones internacionales del Estado de Chile y, sobre todo, considerando que el principio de jurisdicción universal y de prohibición absoluta de la desaparición forzada de personas se encuentran formando parte del dominio del ius cogens. 